\title{
Retrieval of aerosol optical depth over land based on a time series technique using MSG/SEVIRI data
}

\author{
L. Mei ${ }^{1,9}$, Y. Xue ${ }^{1,2}$, G. de Leeuw ${ }^{3,4,5}$, T. Holzer-Popp ${ }^{6}$, J. Guang ${ }^{1}$, Y. Li ${ }^{1,9}$, L. Yang ${ }^{7}$, H. Xu ${ }^{1,9}, X^{\text {X. Xu }}{ }^{8,9}$, C. Li $^{8,9}$,

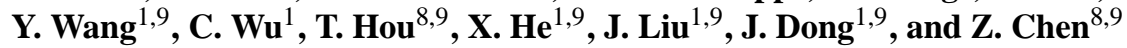 \\ ${ }^{1}$ State Key Laboratory of Remote Sensing Science, jointly sponsored by the Institute of Remote Sensing Applications of \\ Chinese Academy of Sciences and Beijing Normal University, Institute of Remote Sensing Applications, Chinese Academy \\ of Sciences, Beijing 100101, China \\ ${ }^{2}$ Faculty of Computing, London Metropolitan University, 166-220 Holloway Road, London N7 8DB, UK \\ ${ }^{3}$ Department of Physics, University of Helsinki, Helsinki, Finland \\ ${ }^{4}$ Finnish Meteorological Institute, Climate Change Unit, Helsinki, Finland \\ ${ }^{5}$ Netherlands Organisation for Applied Scientific Research TNO, Utrecht, The Netherlands \\ ${ }^{6}$ German Remote Sensing Data Center, German Aerospace Center, Oberpfaffenhofen, 82234 Wessling, Germany \\ ${ }^{7}$ School of Geography, Beijing Normal University, Beijing, China \\ ${ }^{8}$ Center for Earth Observation and Digital Earth, Chinese Academy of Sciences, No.9 Dengzhuang South Road, Haidian \\ District, Beijing 100094, China \\ ${ }^{9}$ University of the Chinese Academy of Sciences, Beijing 100049, China
}

Correspondence to: L. Mei (meilinlu@163.com), Y. Xue (yxue@irsa.ac.cn)

Received: 20 September 2011 - Published in Atmos. Chem. Phys. Discuss.: 3 February 2012

Revised: 2 August 2012 - Accepted: 23 September 2012 - Published: 10 October 2012

\begin{abstract}
A novel approach for the joint retrieval of aerosol optical depth (AOD) and aerosol type, using Meteosat Second Generation - Spinning Enhanced Visible and Infrared Imagers (MSG/SEVIRI) observations in two solar channels, is presented. The retrieval is based on a Time Series (TS) technique, which makes use of the two visible bands at $0.6 \mu \mathrm{m}$ and $0.8 \mu \mathrm{m}$ in three orderly scan times ( $15 \mathrm{~min}$ interval between two scans) to retrieve the AOD over land. Using the radiative transfer equation for plane-parallel atmosphere, two coupled differential equations for the upward and downward fluxes are derived. The boundary conditions for the upward and downward fluxes at the top and at the bottom of the atmosphere are used in these equations to provide an analytic solution for the AOD. To derive these fluxes, the aerosol single scattering albedo (SSA) and asymmetry factor are required to provide a solution. These are provided from a set of six pre-defined aerosol types with the SSA and asymmetry factor. We assume one aerosol type for a grid of $1^{\circ} \times 1^{\circ}$ and the surface reflectance changes little between two subsequent observations. A $k$-ratio approach is used in the inversion to find the best solution of atmospheric properties
\end{abstract}

and surface reflectance. The $k$-ratio approach assumes that the surface reflectance is little influenced by aerosol scattering at $1.6 \mu \mathrm{m}$ and therefore the ratio of surface reflectances in the solar band for two subsequent observations can be wellapproximated by the ratio of the reflectances at $1.6 \mu \mathrm{m}$. A further assumption is that the surface reflectance varies only slightly over a period of $30 \mathrm{~min}$. The algorithm makes use of numerical minimisation routines to obtain the optimal solution of atmospheric properties and surface reflectance by selection of the most suitable aerosol type from pre-defined sets.

A detailed analysis of the retrieval results shows that it is suitable for AOD retrieval over land from SEVIRI data. Six AErosol RObotic NETwork (AERONET) sites with different surface types are used for detailed analysis and 42 other AERONET sites are used for validation. From 445 collocations representing stable and homogeneous aerosol type, we find that $>75 \%$ of the MSG-retrieved AOD at 0.6 and $0.8 \mu \mathrm{m}$ values compare favourably with AERONET observed AOD values, within an error envelope of $\pm 0.05 \pm 0.15 \tau$ and a high correlation coefficient $(R>0.86)$. The AOD datasets derived 
using the TS method with SEVIRI data is also compared with collocated AOD products derived from NASA TERRA and AQUA MODIS (The Moderate-resolution Imaging Spectroradiometer) data using the Dark Dense Vegetation (DDV) method and the Deep Blue algorithms. Using the TS method, the AOD could be retrieved for more pixels than with the NASA Deep Blue algorithm. This method is potentially also useful for surface reflectance retrieval using SEVIRI observations. The current paper focuses on AOD retrieval and analysis, and the analysis and validation of reflectance will be given in a following paper.

\section{Introduction}

A crucial issue with using satellite images to retrieve aerosol properties is the difficulty of effectively separating and explicitly describing contributions from reflections by the underlying surface and from back-scattering by semitransparent aerosol particles to the signal observed by the satellite-based instrument at the top of the atmosphere (TOA) (Hsu et al., 2004; Martonchik, 2009; Govaerts et al., 2010; Varotsos et al. 2006). This problem is generally ill-posed or under-constrained. The problem is particularly challenging for satellite remote sensing over land, especially over bright surfaces. In that case, the contribution of aerosols reflection to the signal observed by satellites is very small compared to the surface contribution, which introduces uncertainty into the process of aerosol properties retrieval. Long term observation networks such as the Sky radiometer Network (SKYNET) (http://atmos.cr.chiba-u.ac.jp/) and AERONET (AErosol RObotic NETwork: http://aeronet.gsfc.nasa.gov/) (Holben et al., 1998) as well as other regional aerosol experimental campaigns such as INDian Ocean Experiment (INDOEX) (http://www-indoex.ucsd.edu/) and Ganges Valley Aerosol Experiment (GVAX) (www.arm.gov/campaigns/ amf2011gvax) could provide good datasets for atmosphere component analysis and modeling validation.

Present-day approaches for satellite remote sensing of aerosol properties over land can be grouped into three main categories (Tang et al. 2005): (1) retrieval based on detection of aerosol over dark surfaces from single pass satellite images; (2) use contrast reduction (or the blurring effect) of images from satellite multi-passes and (3) polarization. The first approach has been widely applied to multi-spectral imagers such as the Moderate Resolution Imaging Spectroradiometer (MODIS) and the Sea-viewing Wide Field-of-view Sensor (SeaWiFS) and to multi-angle imagers such as the Along-Track Scanning Radiometer (ATSR) and the Multiangle Imaging SpectroRadiometer (MISR). Among multispectral imagers, the Dark Dense Vegetation (DDV) method is the most popular algorithm. It relies primarily on the use of low reflectance pixels or dark targets with low reflectance (Kaufman, 1993; Kaufman et al., 1990; Kaufman and Sendra, 1988) and requires prior knowledge of accurate ground surface reflectance (King et al., 1992). One major limitation of the MODIS DDV approach is that when the surface reflectance at $2.1 \mu \mathrm{m}$ is above 0.15 , no retrievals are performed and the assumption of transparency in this channel is not considered valid (Kaufman et al., 1997; Hsu et al., 2004; Remer et al., 2005; Levy et al., 2010). For the retrieval over bright surfaces such as arid, semi-arid and urban areas, Hsu et al. (2004) developed the Deep Blue algorithm which uses the fact that the surface is much darker in the blue spectral region than that at longer wavelengths. This approach has an estimated accuracy of 20-30\%.

In aerosol retrieval algorithms developed for multi-angular imagers, it is often assumed that the wavelength dependence of the surface Bidirectional Reflectance Distribution Function (BRDF) shape is negligible in comparison with the wavelength dependence of the surface and atmospheric scattering properties (Flowerdew and Haigh, 1995). This assumption can be used because the scattering elements of the surface are much larger than the wavelengths used in the retrieval procedure, and therefore the angular variation of the surface reflectance is often dominated by wavelengthindependent geometric effects (Grey et al., 2006). This approach is used in the dual view algorithm (Veefkind et al., 1999) and the Swansea algorithm (Grey et al., 2006) for ATSR data and the MISR algorithm (Diner et al., 2005). North et al. (1999) developed this approach further by considering the variation of the diffuse fraction of light with the wavelength.

Aerosol products from polar-orbiting satellite sensors, such as MODIS, represent a significant improvement over those from other satellite imagers, which are generally only based on single or dual channel reflectance as described above. However, polar-orbiting satellites are restricted to overpasses at a fixed local time, and thus cannot resolve the diurnal cycle and temporal evolution of aerosols (Spörl and Deneke, 2011).The Geostationary Operational Environmental Satellites-8 (GOES 8) imager and similar geostationary satellites with high temporal resolution are capable of capturing the aerosol diurnal variation. This capability can be used to for air quality and transport studies and to further reduce the uncertainties in the current aerosol forcing estimations caused by high temporal variations of aerosol properties, thereby playing a role complementary to global AOD retrievals from polar orbiting satellites.

The approach using contrast reduction (or the blurring effect) of images from satellite multi-passes is quite popular for geostationary satellites. The main idea is to build a reference surface reflectance dataset by selecting the second darkest value observed for each pixel during a certain time period, which also avoids the effect of shadows, and then to perform aerosol retrieval over land using a Look-Up Table (LUT) for various Rayleigh scattering corrected surface reflectances and aerosol models for a range of AODs. Knapp et al. $(2002,2005)$ found that a 14-day period was a good 
compromise for the length of the time series and the influence of changes in surface reflectance and aerosol loading. One limitation of this approach is that it does not work for pixels covering a mixture of different ground surfaces, and retrieval values of AOD in some parts are negative. Mei et al. (2011) developed a method based on the assumptions that the TOA reflectance increases with increasing aerosol load and that the surface reflectance changes very little over a certain period of time. The contributions from the surface and aerosol were chosen based on AERONET information, and both of them vary in a different way with time. The variation of surface reflectance is somewhat predictable based on solar angles and vegetation changes, but aerosol properties depend on the source regions and transport which are hard to predict. Wang et al. (2003) used 30 days of half-hourly, high temporal resolution GOES 8 imager data and radiative transfer calculations to retrieve dust AOD over the Atlantic Ocean $\left(14^{\circ} \mathrm{N}-26^{\circ} \mathrm{N}, 73^{\circ} \mathrm{W}-63^{\circ} \mathrm{W}\right)$ during the Puerto Rico Dust Experiment (PRIDE).

The key advantage of the polarization approach is its ability to systematically correct for the surface contribution (Deuze, et al., 2001; Deuze, et al., 1993; Herman, et al., 1997). The main contribution of land surfaces to the TOA polarised portion of total reflected radiance at short wavelengths is generally smaller and less variable compared to that of the atmosphere and can be more easily modelled and removed in principle. However, this method is only suitable for large scattering (large aerosol loads), small aerosol particles (Deuze, et al., 2001) or small phase angles (Rondeaux and Herman, 1991; Breon et al., 1995).

Unlike traditional geostationary satellites, MSG has three narrow spectral bands in the solar spectrum (at 0.63, 0.81 and $1.64 \mu \mathrm{m}$ ), in addition to a wide HRV band. A variety of approaches for AOD retrieval from Meteosat Second Generation-Spinning Enhanced Visible and Infrared Imagers (MSG/SEVIRI) data has been published in the literature. This includes studies to retrieve AOD over ocean using MSG/SEVIRI, which demonstrates good comparison of the MSG/SEVIRI AOD with AERONET observations (Thieuleux et al., 2005; Bennouna et al., 2009). As to AOD retrieval over land using MSG/SEVIRI data, Popp et al. (2007) used a "background method" which is not suitable for bright surfaces with absorbing aerosol to retrieve the AOD. Bernard et al. (2011) evaluated this method, confirming that this method is suitable for most Europe areas. Carrer et al. (2010) put forward daily estimates of AOD over land based on a directional and temporal analysis of visible observations from MSG/SEVIRI. Govaerts et al. (2010) developed a joint retrieval method of surface reflectance and AOD from MSG/SEVIRI observations with an optimal estimation approach. Meanwhile, Some mature retrieval algorithms are also "transplanted" for MSG/SEVIRI AOD retrieval, such as an operational algorithm used to retrieve AOD over ocean for the Advanced Very High Resolution Radiometer (AVHRR) (Brindley and Ignatov, 2006) and the Oxford-RAL Aerosol

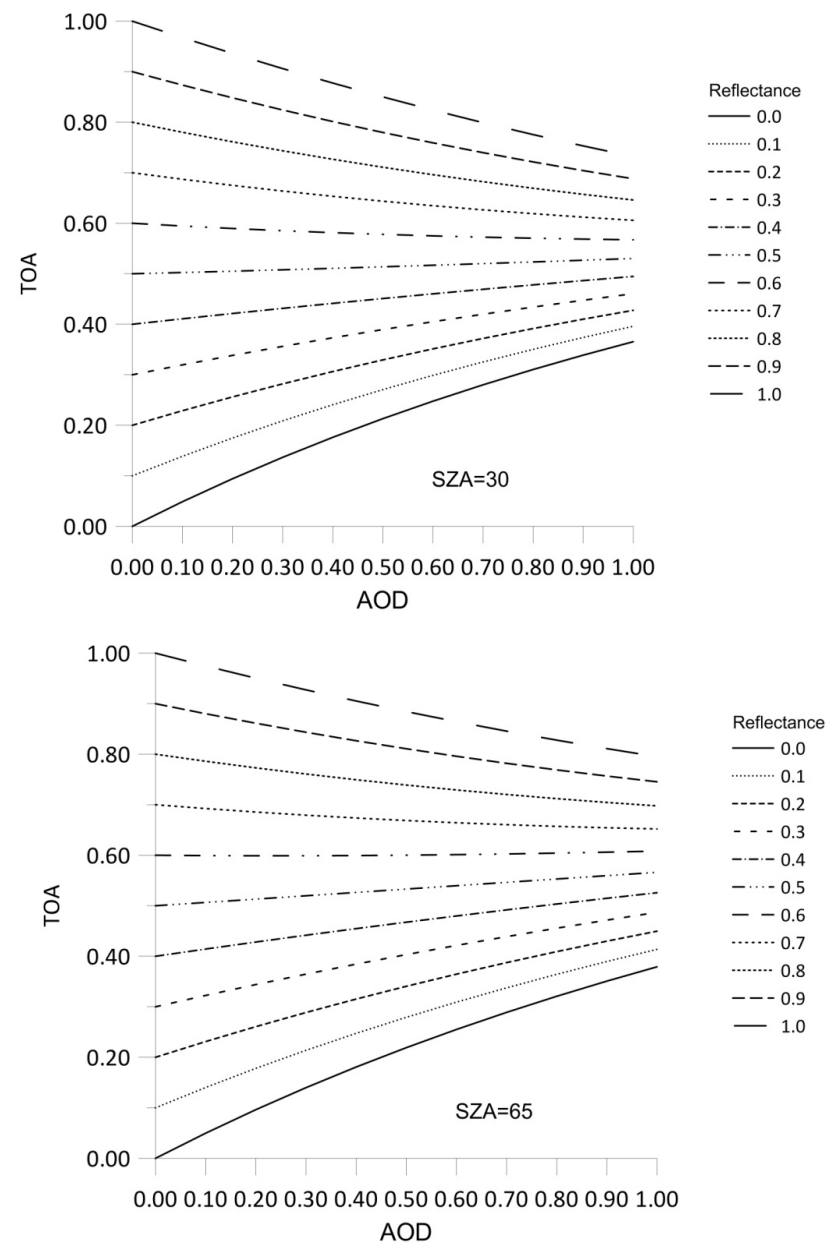

Fig. 1. Sensitivity analysis for analytical solution of the TOA reflectance as function of AOD for different surface reflectances and for two Solar Zenith Angles (SZA).

and Cloud (ORAC) method (Bulgin et al., 2011). The method presented by Brindley and Ignatov (2006) can provide both AOD and size information for mineral aerosol. However, most AOD retrieval algorithms over land focus on daily or hourly average AOD products (Bernard et al., 2009, 2011; Govaerts et al., 2010) or certain aerosol type (Brindley and Ignatov, 2006).

To address the shortcomings from polar-orbiting satellites and also existing algorithms for MSG/SEVIRI, we present a novel method to utilize the MSG/SEVIRI data to obtain aerosol products (including AOD and aerosol type information) at SEVIRI's $15 \mathrm{~min}$ temporal resolution. The retrieval methodology is described in Sect. 2. The retrieval results are discussed in Sect. 4 following the introduction of data used for retrieval in Sect. 3. Conclusions are presented in Sect. 5. 


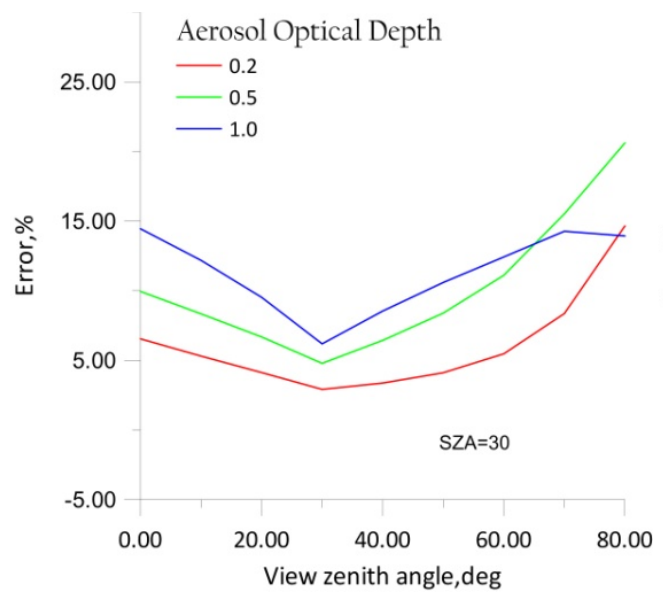

a

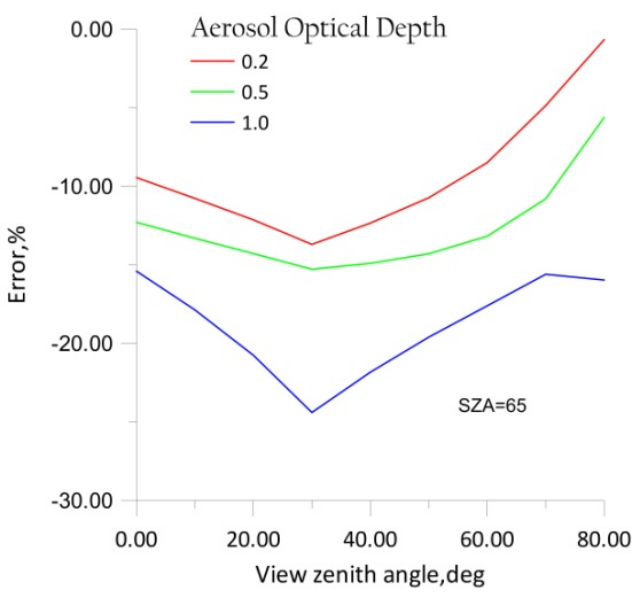

b

Fig. 2. Error of analytical solution computations of the TOA reflectance with continental (a) and neutral (b) aerosol at different solar zenith angle dependent on the view zenith angle with AOD equal to 0.2 (red), 0.5 (green) and 1.0 (blue). We can see that the analytical solution overestimates for continental aerosol (a) and underestimates for neutral aerosol (b).

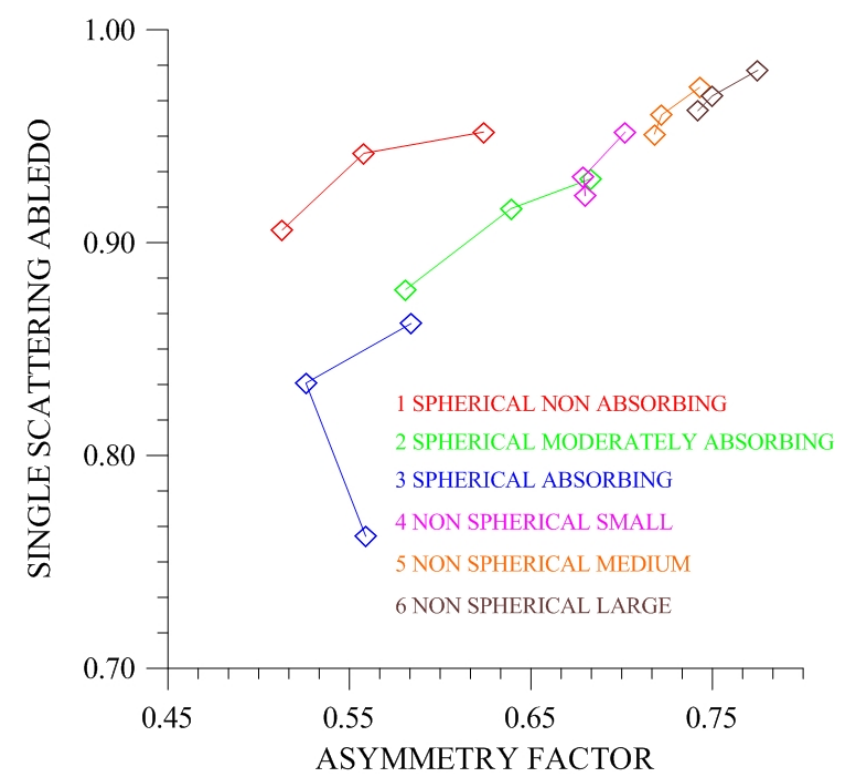

Fig. 3. Aerosol classes in $(g, \varpi)$ space derived from the analysis of AERONET observations at the SEVIRI solar channel wavelengths (Adapted from Govaerts et al., 2010). Three squares with same colours refer to three wavelengths (See Table 1 for details).

\section{Retrieval strategy}

\subsection{Retrieval method}

The basic equation for the transfer of radiation in a planeparallel atmosphere can be written in the form (Liou, 2002):

$$
\begin{aligned}
& \mu \frac{d I(\tau, \Omega)}{d \tau}=I(\tau, \Omega)-\frac{\varpi}{4 \pi} \int_{4 \pi} I\left(\tau, \Omega^{\prime}\right) P\left(\Omega, \Omega^{\prime}\right) d \Omega^{\prime} \\
& -\frac{\varpi}{4 \pi} F_{\Theta} P\left(\Omega,-\Omega_{0}\right) \exp \left(-\frac{\tau}{\mu_{0}}\right)-(1-\varpi) B\left[T_{e}(\tau)\right]
\end{aligned}
$$

Here $\Omega$ stands for the direction, contains both zenith angle and azimuth angle and the definition can be found in Fig. 3.16 at (Liou, 2002) in Sect. 3.4.1. A glossary of symbols used in this paper is given in the Appendix. Once the phase function has been expressed in terms of Legendre polynomials, Eq. (1) can be decomposed into two differential equations: one for the upward flux, and the other one for the downward flux. These equations are as follows:

$$
\begin{aligned}
& \frac{d F^{\uparrow}(\tau)}{d \tau}=\gamma_{1} F^{\uparrow}(\tau)-\gamma_{2} F^{\downarrow}(\tau)-\gamma_{3} \varpi F_{\Theta} \exp \left(-\frac{\tau}{\mu_{0}}\right) \\
& \frac{d F^{\downarrow}(\tau)}{d \tau}=\gamma_{1} F^{\uparrow}(\tau)-\gamma_{1} F^{\downarrow}(\tau)-\left(1-\gamma_{3}\right) \varpi F_{\Theta} \exp \left(-\frac{\tau}{\mu_{0}}\right)
\end{aligned}
$$

With the following boundary conditions for the upward and downward fluxes at the top and the bottom of the atmosphere,

$$
\begin{aligned}
& \frac{F^{\uparrow}(\tau=0)}{F^{\downarrow}(\tau=0)}=A^{\prime} \\
& \frac{F^{\uparrow}\left(\tau=\tau_{0}\right)}{F^{\downarrow}\left(\tau=\tau_{0}\right)}=A
\end{aligned}
$$

the following equation is derived:

$$
A=\frac{\left[a+c\left(\Gamma-A^{\prime}\right)\right] e^{k \tau}+\left[b+c\left(A^{\prime} \Gamma-1\right)\right] \Gamma e^{-k \tau}+\left(\Gamma^{2}-1\right) G^{+} e^{-\frac{\tau}{\mu_{0}}}}{\left[a+c\left(\Gamma-A^{\prime}\right)\right] \Gamma e^{k \tau}+\left[b+c\left(A^{\prime} \Gamma-1\right)\right] e^{-k \tau}+\left(\Gamma^{2}-1\right) G^{-} e^{-\frac{\tau}{\mu_{0}}}}
$$


where

$$
\begin{aligned}
& a=G^{+}-G^{-} \Gamma \\
& b=G^{-}-G^{+} \Gamma \\
& c=F_{\Theta} \mu_{0} \\
& G^{+}=\frac{\mu_{0}^{2} \varpi F_{\Theta}}{\left(k \mu_{0}\right)^{2}-1}\left[\left(\gamma_{1}-\frac{1}{\mu_{0}}\right) \gamma_{3}+\gamma_{2} \gamma_{4}\right] \\
& G^{-}=\frac{\mu_{0}^{2} \varpi F_{\Theta}}{\left(k \mu_{0}\right)^{2}-1}\left[\left(\gamma_{1}+\frac{1}{\mu_{0}}\right) \gamma_{4}+\gamma_{2} \gamma_{3}\right] \\
& k^{2}=\gamma_{1}^{2}-\gamma_{2}^{2} \\
& F_{\Theta}=S\left(\frac{r_{0}}{r}\right)^{2} \mu_{0} \\
& \Gamma=\frac{\gamma_{1}-k}{\gamma_{2}} \\
& \gamma_{1}=\frac{1}{4}[7-(4+3 g) \varpi] \\
& \gamma_{2}=-\frac{1}{4}[1-(4-3 g) \varpi] \\
& \gamma_{3}=\frac{1}{4}\left(2-3 g \mu_{0}\right) \\
& \gamma_{4}=1-\gamma_{3}
\end{aligned}
$$

and $r_{0}$ is the mean distance between earth and sun, $S$ is the solar constant, $\mu_{0}$ is the cosine of the solar zenith angle.

Liou (2002) suggested setting $\varpi=0.999999$ in all of the above equations when there is no absorbance, and a simple analytical solution has been derived by Xue and Cracknell (1995). For conservative scattering $(\omega=1)$, simpler solutions can be derived with one of the eigenvalues. However, here we need two eigenvalues in order to derive a relationship between reflectance and AOD. In practice, however, we may set $\omega=0.999999$ and obtain the results for conservative scattering (Liou, 2002). For our model, we assume that the atmospheric optical depth $(\tau)$ consists of two parts: the molecular Rayleigh scattering ( $\left.\tau_{\text {molecular }}\right)$, and the aerosol optical depth $\left(\tau_{\text {aerosol }}\right)$. Therefore, the dimensionless quantity of the optical depth of the whole atmosphere (both Rayleigh optical depth and aerosol optical depth) is as follows:

$\tau=\tau_{\text {molecular }}+\tau_{\text {aerosol }}$

Aerosol plays different roles for different surface type. There is a critical reflectance dividing the positive and negative effects of aerosol and the algorithm is insensitive to AOD during a certain range of this critical reflectance. A primary sensitivity study for the analytical solution is shown in Figs. 1 and 2. In Fig. 1, TOA takes values of 0.0 to 1.0 and solar zenith angle $(\theta)$ takes two different values of $30^{\circ}$ and $65^{\circ}$. From Fig. 1, we can see that the TOA critical reflectance is around 0.5 when $\theta=30^{\circ}$ and 0.6 while $\theta=65$. It is obvious that the AOD sensitivity (the gradient in the graph) depends strongly on the surface reflectance: the AOD sensitivity decreases with increasing reflectance for reflectances smaller than the critical reflectance, and the opposite applies for reflectance larger than critical reflectance. Figure 2 shows estimations of the analytical solution errors obtained by comparison with Second Simulation of the Satellite signal in the Solar Spectrum (6S) computations for different solar zenith angles, for two different aerosol types (continental and neutral). Here the reflectance is equal to 0.3 (very bright surface). These data in Fig. 2 show that the errors of the analytical solution may overestimate for continental aerosol and underestimate for neutral aerosol. We can find that the absolute errors do not exceed $15 \%$ compared with $6 \mathrm{~S}$ (except for neutral type with large AOD). For the continental aerosol type, we can also find that the errors do not exceed $10 \%$ for viewing zenith angles between $20^{\circ}$ and $50^{\circ}$, which are the most probable values for the study area considered here.

\subsection{Aerosol model selection and update}

The use of aerosol models results from the need to provide some prior information on the aerosol physical and chemical properties which determine their radiative properties (Govaerts et al., 2010). One absorption parameter (single scattering albedo, or SSA) and one size parameter (asymmetry factor, denoted as $\mathrm{g}$ ) are sufficient for representing the entire aerosol parameter space (Levy et al., 2007); Other parameters such as size information (mean radius and so on), optical properties (extinction/backscatter ration and so on) (Omar et al., 2005), and fine-mode fractions (FMF) (Kim et al., 2010) have also been used. Govaerts et al. (2010) suggested six aerosol types (spherical non-absorbing, spherical moderately absorbing, spherical absorbing, non-spherical small, non-spherical medium and non-spherical large) that can be used in MSG/SEVIRI AOD retrieval. The aerosol models proposed by Govaerts et al. (2010) and the values of parameters describing each of them are presented in Table 1 and in Fig. 3.

\subsection{Inverse problem}

Modelling studies predict that, for certain pairs of wavelengths, the ratios of the Bidirectional Reflectance Factor (BRF) between wavelengths are approximately constant, irrespective of view direction (North et al., 1999). The angular variation of the surface reflectance is due to the macroscopic structure of the underlying surface (Flowerdew and Haigh, 1995), which is of a much larger scale than the wavelength of incident light (Curier et al., 2009). Therefore, the surface reflectance can be described by a part which describes the variation with wavelength and a part that describes the variation with geometry (Flowerdew and Haigh, 1995). Geostationary satellites, such as MSG, image a certain location every $15 \mathrm{~min}$ and the geometry changes gradually throughout the day due to changes in solar zenith angle. In conditions of relatively stable aerosol loading, this property can be utilised to provide repeated views under different angles of illumination 
Table 1. Properties of the spherical and non-spherical aerosol model in solar band of MSG/SEVIRI derived from AERONET observation (fine model and coarse model parameters come from Govaerts et al., 2010).

\begin{tabular}{lllll|lll}
\hline \multirow{2}{*}{ Aerosol } & Label & \multicolumn{3}{c}{ Spherical } & \multicolumn{3}{c}{ Non-spherical } \\
\cline { 3 - 7 } & & ABSORB & MODABS & NONABS & SMARAD & MEDRAD & LARRAD \\
\hline Fine & $\mathrm{r}_{\mathrm{vf}}$ & 0.155 & 0.221 & 0.179 & 0.145 & 0.172 & 0.202 \\
mode & $\sigma_{\mathrm{f}}$ & 0.404 & 0.497 & 0.426 & 0.500 & 0.636 & 0.627 \\
& $\mathrm{C}_{\mathrm{vf}}$ & 0.083 & 0.094 & 0.101 & 0.037 & 0.033 & 0.043 \\
& $\mathrm{r}_{\mathrm{ef}}$ & 0.143 & 0.195 & 0.164 & 0.129 & 0.141 & 0.165 \\
\hline Coarse & $\mathrm{r}_{\mathrm{vc}}$ & 3.012 & 2.886 & 3.004 & 2.423 & 1.961 & 1.978 \\
mode & $\sigma_{\mathrm{c}}$ & 0.649 & 0.598 & 0.623 & 0.617 & 0.549 & 0.527 \\
& $\mathrm{C}_{\mathrm{vc}}$ & 0.051 & 0.050 & 0.039 & 0.262 & 0.364 & 0.521 \\
& $\mathrm{r}_{\mathrm{ec}}$ & 2.414 & 2.427 & 2.474 & 1.984 & 1.672 & 1.697 \\
\hline $\mathrm{S} \mathrm{S}_{0}$ & & 98.6 & 93.6 & 98.5 & 3.1 & 1.3 & 1.2 \\
\hline $\mathrm{g}$ & 0.6 & 0.58 & 0.68 & 0.62 & 0.68 & 0.72 & 0.74 \\
& 0.8 & 0.53 & 0.64 & 0.56 & 0.68 & 0.73 & 0.75 \\
& 1.6 & 0.56 & 0.58 & 0.51 & 0.70 & 0.74 & 0.78 \\
\hline \multirow{2}{*}{} & 0.6 & 0.86 & 0.93 & 0.95 & 0.92 & 0.95 & 0.96 \\
& 0.8 & 0.834 & 0.92 & 0.94 & 0.93 & 0.96 & 0.97 \\
& 1.6 & 0.76 & 0.88 & 0.91 & 0.95 & 0.97 & 0.98 \\
\hline
\end{tabular}

(Thomas et al., 2009). Under this assumption, the ratio of the surface reflectances at two scan times can be written as follows:

$k_{\lambda}=\frac{A_{1, \lambda}}{A_{2, \lambda}}$

The grand mean absolute error for predicted reflectance with this so-called $k$-approximation is $3.8 \%$ while the Lambertian error is $14.5 \%$ (Flowerdew and Haigh, 1995).

For most continental aerosol types, aerosol extinction decreases with wavelength to the power $n$, with the value of $\mathrm{n}$ depending on aerosol particle size distribution; for continental aerosol $n$ is of the order of 2. Therefore, the AOD at $1.6 \mu \mathrm{m}$ is usually small compared to the AOD in the visible spectrum (de Leeuw, et al., 2007; Curier et al., 2009). However, the SEVIRI $0.8 \mu \mathrm{m}$ band includes a water vapour absorption band close to $0.83 \mu \mathrm{m}$. This may invalidate Eq. (19), so this band should be corrected to remove the effect of water and other gases (http://modis.gsfc.nasa.gov/data/atbd/ atmos_atbd.php).

Because the SEVIRI scans the Earth disk every 15 minutes, the reflectance varies only slightly within the remaining solutions of the time-series (Knapp et al., 2005; Kim et al., 2008; Govaerts et al., 2010). The predefined aerosol type that fits the following equation best is the so-called true aerosol type.

$\varepsilon=\min \left\{\sum_{t} \sum_{i=1}^{n}\left(A_{\lambda_{t, i}}^{m}-A_{\lambda_{t+1, i}}^{m}\right)^{2}\right\}$

In Eq. (21), $\varepsilon$ is the minimal difference between surface reflectance of two subsequent observations for each prede- fined aerosol type. $t$ is different scan times, $i$ is different solar bands ( $i$ was named as channel number in Sect. 3 adopted from MSG Algorithm Theoretical Basis Documents, MSG/ATBD) and $\mathrm{m}$ is the number of predefined aerosol types, here $m=6$.

Aerosol type selection is a major problem during retrieval. Kokhanovsky et al. (2010) made an inter-comparison of several satellite aerosol retrieval algorithms and concluded that the error caused by the selection of the wrong aerosol type can be larger than $100 \%$. Levy et al. (2007) suggested that satellite images should be mapped onto a $1^{\circ} \times 1^{\circ}$ grid while aerosol in one grid can be defined as one single type. We assumed that the aerosol type in a restricted geographical area of $1^{\circ} \times 1^{\circ}$ would be a single aerosol type. For each processed SEVIRI pixel, the solution was calculated independently for each predefined aerosol class. The details of all aerosol types in each pixel in an area of $1^{\circ} \times 1^{\circ}$ were statistically analysed as following.

1. First, we assign one aerosol type from those six aerosol types for all pixels in the grid.

2. For each pixel in the grid, we calculate the surface reflectance using the above method for three subsequent SERIVI scans. Equation (21) is used to calculate $\varepsilon$ for the surface reflectance difference between two subsequent scans. With our assumptions, the surface reflectance between two subsequent observation times (15 min) should change little and ideally, $\varepsilon$ should be zero. 


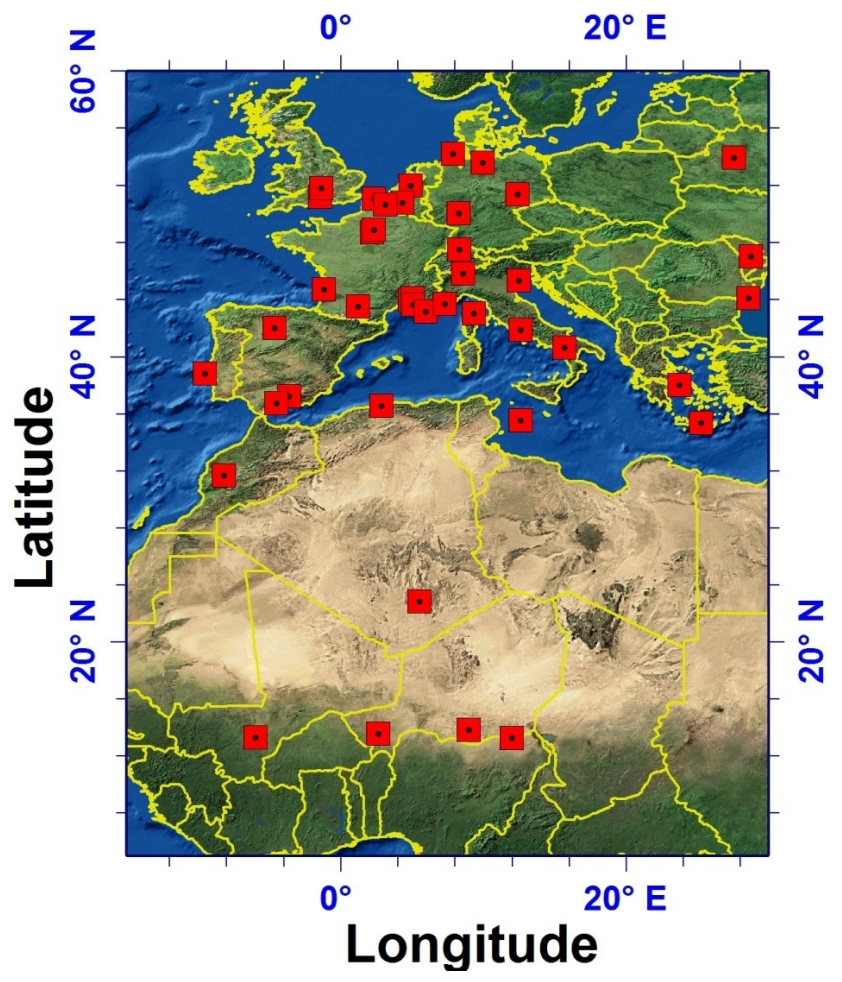

Fig. 4. AERONET sites (red squares) selected for validation of the TS results $\left(15^{\circ} \mathrm{W}-30^{\circ} \mathrm{E}, 5^{\circ} \mathrm{N}-60^{\circ} \mathrm{N}\right)$.

Table 2. Band solar irradiance at 1 AU (astronomical unit) (provided by EUMESAT).

\begin{tabular}{ccc}
\hline Channel & Wavelength $(\mu \mathrm{m})$ & Solar irradiance \\
\hline 1 & 0.8 & 65.2065 \\
2 & 0.6 & 73.1869 \\
3 & 1.6 & 61.9923 \\
\hline
\end{tabular}

3. We change the aerosol type and repeat steps (1) and (2). We can obtain six $\varepsilon$ values for six aerosol types. We assume that the aerosol type with the smallest $\varepsilon$ value is the right aerosol type for the pixel in the grid. We count how many pixels for each aerosol type in the grid. The aerosol type with the highest number of pixels is chosen as the most suitable aerosol type for the grid.

4. By repeating steps (1) to (3), we then obtain the aerosol type in the whole study area and reprocessed the AOD using the updated aerosol type.

\section{Data}

The SEVIRI on the MSG satellite can observe the Earth in 12 spectral channels with a resolution of $3 \mathrm{~km}$ at the sub-satellite point, providing image data which is critical for operational
Table 3. Forty-two selected AERONET stations in Africa and Europe and their locations (latitude, longitude and elevation) for the aerosol retrieval validation.

\begin{tabular}{|c|c|c|c|}
\hline Name & Longitude & Latitude & Elevation (m) \\
\hline Arcachon & -1.163222 & 44.663528 & 11 \\
\hline ATHENS-NOA & 23.775 & 37.988 & 130 \\
\hline Autilla & -4.603056 & 41.997222 & 873 \\
\hline Avignon & 4.878067 & 43.93275 & 32 \\
\hline Banizoumbou & 2.66475 & 13.541167 & 250 \\
\hline Blida & 2.880556 & 36.508333 & 230 \\
\hline Cabauw & 4.927 & 51.971 & -1 \\
\hline Brussels & 4.35 & 50.783332 & 120 \\
\hline Cabo_da_Roca & -9.5 & 38.783333 & 140 \\
\hline Carpentras & 5.058333 & 44.083333 & 100 \\
\hline Chilbolton & -1.43698 & 51.14446 & 88 \\
\hline DMN_Maine_Soroa & 12.023067 & 13.216717 & 350 \\
\hline Dunkerque & 2.368117 & 51.03535 & 0 \\
\hline Eforie & 28.632222 & 44.075 & 40 \\
\hline Ersa & 9.359289 & 43.003669 & 80 \\
\hline FORTH_CRETE & 25.282417 & 35.332694 & 20 \\
\hline Granada & -3.605 & 37.164 & 680 \\
\hline Hamburg & 9.973333 & 53.568333 & 105 \\
\hline Helgoland & 7.887361 & 54.177861 & 33 \\
\hline IER_Cinzana & -5.933867 & 13.278433 & 285 \\
\hline IFT-Leipzig & 12.435278 & 51.3525 & 125 \\
\hline IMAA_Potenza & 15.72 & 40.6 & 820 \\
\hline Ispra & 8.6267 & 45.80305 & 235 \\
\hline Laegeren & 8.351389 & 47.480278 & 735 \\
\hline Lampedusa & 12.631667 & 35.516667 & 45 \\
\hline Lille & 3.141667 & 50.611667 & 60 \\
\hline Mainz & 8.3 & 49.999 & 150 \\
\hline Malaga & -4.4775 & 36.715 & 40 \\
\hline Minsk & 27.601 & 53.92 & 200 \\
\hline Moldova & 28.8156 & 47.0001 & 205 \\
\hline Palaiseau & 2.208333 & 48.7 & 156 \\
\hline Paris & 2.333333 & 48.866667 & 50 \\
\hline Rome_Tor_Vergata & 12.647333 & 41.83955 & 130 \\
\hline Saada & -8.15583 & 31.62583 & 420 \\
\hline Salon_de_Provence & 5.120278 & 43.605556 & 60 \\
\hline Seysses & 1.259722 & 43.503333 & 179 \\
\hline Tamanrasset_INM & 5.53 & 22.79 & 1377 \\
\hline Toulon & 6.009444 & 43.135556 & 50 \\
\hline Venise & 12.5083 & 45.3139 & 10 \\
\hline Villefranche & 7.328889 & 43.683889 & 130 \\
\hline Wytham_Woods & -1.3325 & 51.770278 & 160 \\
\hline Zinder_Airport & 8.990233 & 13.776683 & 456 \\
\hline
\end{tabular}

forecasting needs. A key feature of SEVIRI is its ability to continuously image the Earth every 15 minutes. Commonly, the reflectance $A^{\prime}(i)$ used in the retrieval algorithms, can be derived from the satellite-measured radiance assuming that the surface acts as a Lambertian reflector and the atmosphere is horizontally uniformly stratified using the following equation adopted from MSG ATBD: 

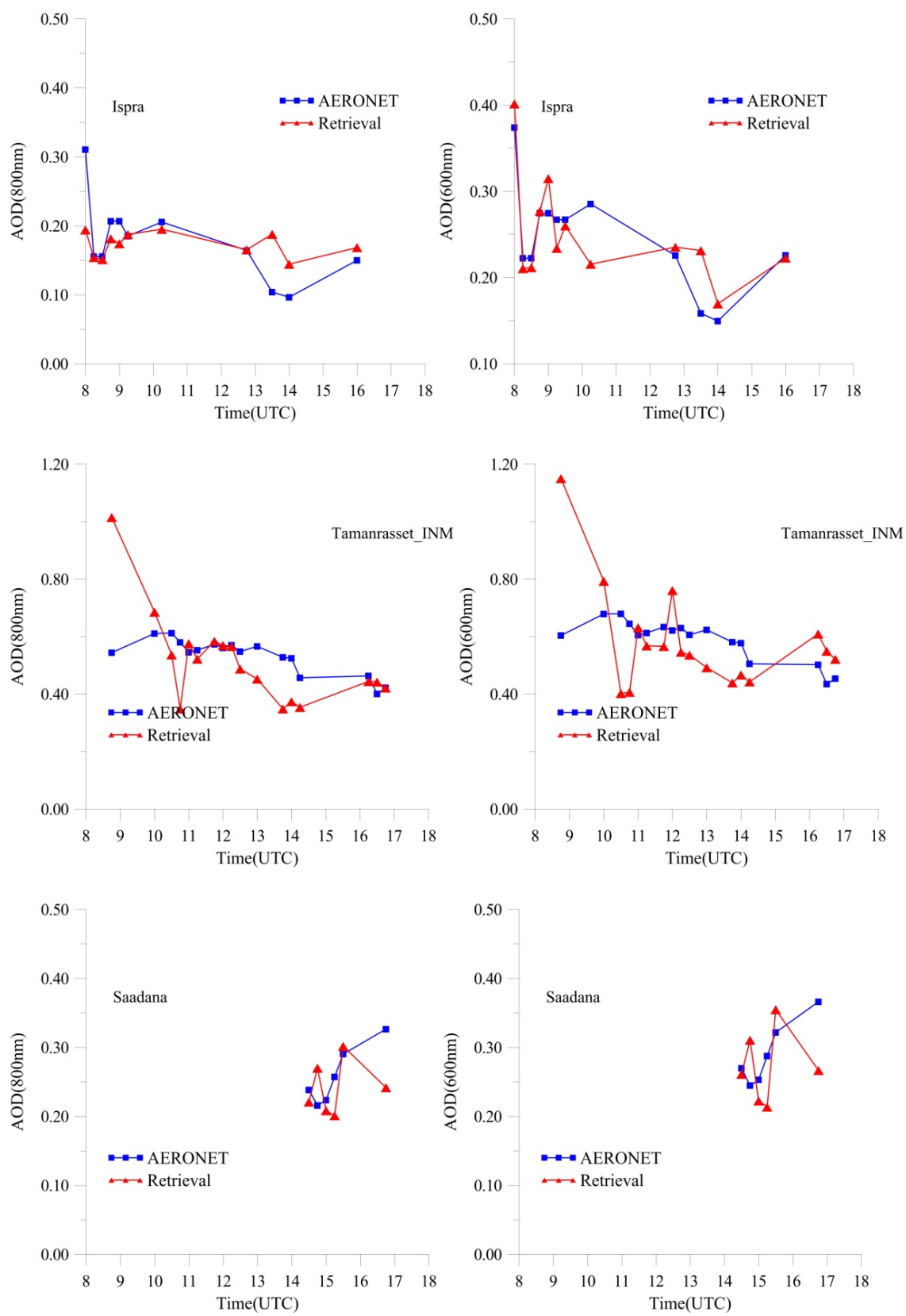

Fig. 5. Time-series of MSG/SEVIRI and AERONET AOD at $0.8 \mu \mathrm{m}$ and $0.6 \mu \mathrm{m}$ from 08:00 UTC to 18:00 UTC on 14 April 2010 at Ispra, Tamanrasset_INM, Saada, Carpentras, Hamburg and IER_Cinzana sites.

$A^{\prime}(i)=\frac{\pi \times I(i) \times r^{2}(t)}{L \times \cos (\theta(t, x))}$

where $I(i)$ is the measured radiance in $\mathrm{mW} \mathrm{m}{ }^{-2} \mathrm{sr}^{-1}\left(\mathrm{~cm}^{-1}\right)^{-1}, r(t)$ is the Sun-Earth distance in astronomical units (AU) at scan time $\mathrm{t}(r(t)=r), L$ is the band solar irradiance at $1 \mathrm{AU}$ in $\mathrm{m} \mathrm{Wm}^{-2} \mathrm{sr}^{-1}\left(\mathrm{~cm}^{-1}\right)^{-1}$ (shown in Table 2), $\theta(t, x)$ is the solar zenith angle in radians at scan time $t$ and location $x$ and $i$ is the channel number.

The AERONET sun photometer network has been developed to provide independent data for the validation of both airborne and space-borne aerosol observations (Holben et al., 1998). For the validation of the results from the TS algorithm forty-two AERONET sites were selected (shown in Fig. 4). Table 3 shows information about the latitude, longitude, and elevation of the selected AERONET sites.

The middle wavelengths of the MSG/SEVIRI visible bands are 0.6 and $0.8 \mu \mathrm{m}$. These wavelengths are not available from the AERONET sun photometers. Therefore, the natural logarithm of AOD has been fitted as a quadratic polynomial of the natural logarithm of the wavelength (fitting 

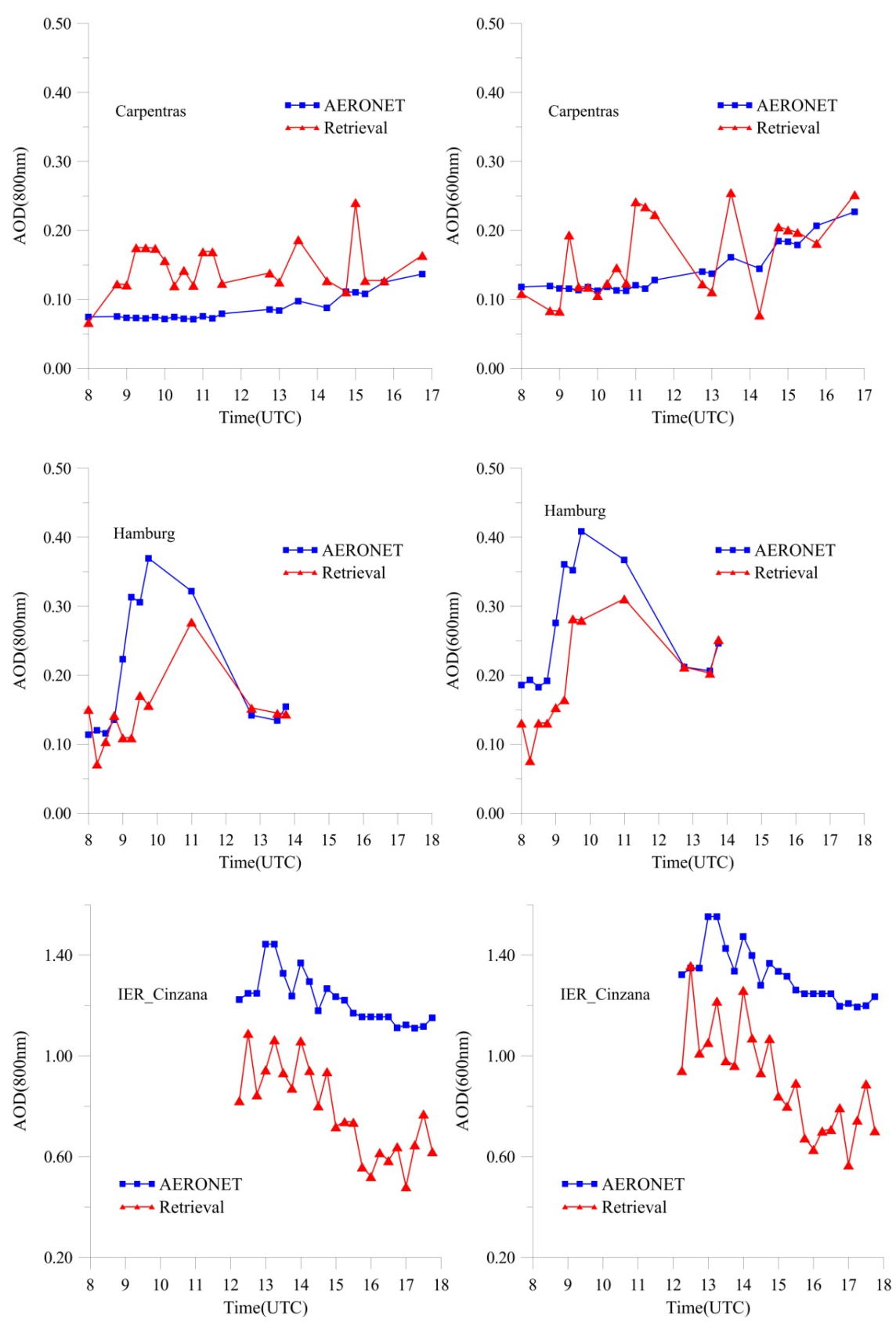

Fig. 5. Continued.

error of about 0.01-0.02) (Eck et al., 1999) to provide the 0.6 and $0.8 \mu \mathrm{m}$ AOD at the AERONET sites for validation of the MSG/SEVIRI AOD. Wavelengths of 0.44, 0.675 and $0.87 \mu \mathrm{m}$ were selected for fitting:

$\ln \tau(\lambda)=a_{0}+a_{1} \ln \lambda+a_{2}(\ln \lambda)^{2}$

where $\tau(\lambda)$ is AOD at wavelength $\lambda$ and $a_{0}, a_{1}$ and $a_{2}$ are polynomial coefficients.

\section{Results and analysis}

In Sect. 4, we mainly focus on the comparison between satellite-derived AOD results using the TS algorithm and AERONET ground-based measurements in two aspects: 1) the statistical analysis using scatter plots between satellitederived AOD products and AERONET AOD measurements (AERONET measurements have been interpolated to the same wavelengths as satellite using the method described in Sect. 3.2) time series analysis to see the variability of AODs during the day. 


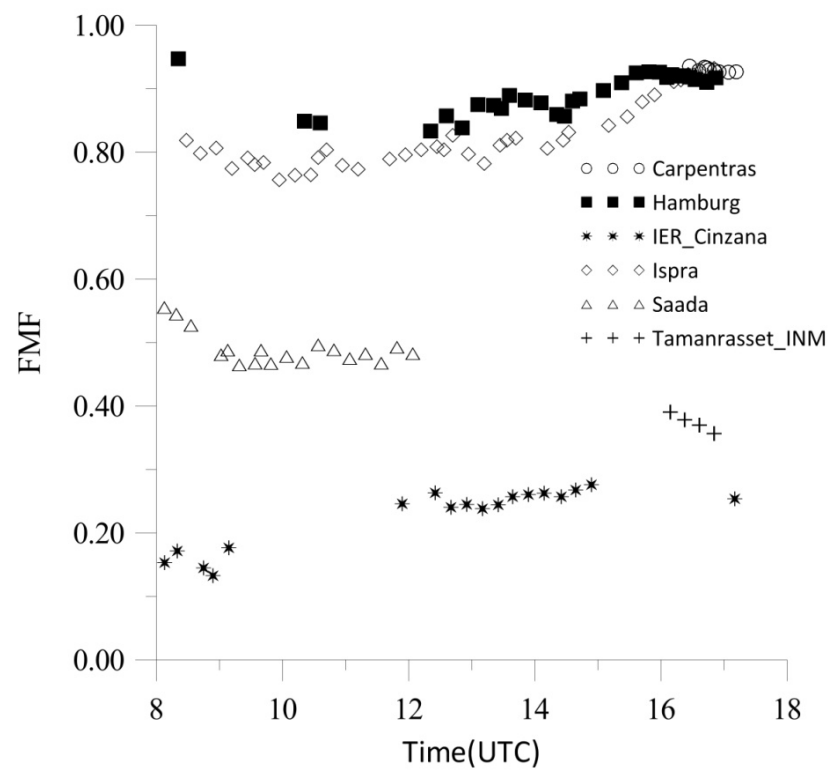

Fig. 6. Various FMF values measured between 08:00 and 18:00 UTC on 14 April 2010 at six selected AERONET sites.

\subsection{Time series analysis of AOD}

A spatial-temporary matching-up method (Ichoku et al., 2002; Remer et al., 2002, 2004; Chen et al., 2005) is used. We use the average value of a certain time (that is during $7.5 \mathrm{~min}$ before and $7.5 \mathrm{~min}$ after satellite overpass time) in windows of $1 \times 1,3 \times 3$ and $5 \times 5$ pixels. We calculate the average and standard deviation for different windows $(1 \times 1$ need no calculation). If the average value of different windows does not change much, we only use $1 \times 1$, otherwise, we choose the average value for a certain window size with the smallest deviation. Forty-two AERONET sites were used for validation and a detailed analysis for the validation data was made to eliminate "outliers". Representative points were selected to provide a range of different surface types and aerosol models. As an example, shorter time-series (from 08:00 UTC to 18:00 UTC on 14 April 2010) of MSG/SEVIRI derived AOD at $0.8 \mu \mathrm{m}$ and $0.6 \mu \mathrm{m}$ and corresponding AERONET observations of AOD at the AERONET sites in Carpentras $\left(5.058^{\circ} \mathrm{E}, 44.083^{\circ} \mathrm{N}\right)$, Hamburg $\left(9.973^{\circ} \mathrm{E}, 53.568^{\circ} \mathrm{N}\right)$, Ispra $\left(8.627^{\circ} \mathrm{W}, 45.803^{\circ} \mathrm{N}\right)$, Tamanrasset_INM $\left(5.53^{\circ} \mathrm{E}\right.$, $\left.22.79^{\circ} \mathrm{N}\right)$, Saada $\left(8.156^{\circ} \mathrm{W}, 31.626^{\circ} \mathrm{N}\right)$ and IER_Cinzana $\left(5.934^{\circ} \mathrm{E}, 13.278^{\circ} \mathrm{N}\right)$ are presented in Fig. 5. In general, there is good agreement between the MSG and AERONET estimated AOD at these two bands at four sites. For example, quite good agreement is found in Ispra during the whole day; $90 \%$ of the values show differences smaller than 0.05 . Note that the absolute error of typical AOD retrieval approaches is larger than 0.05 (Mishchenko et al., 2007). Occasionally, however, there are spikes in the MSG observations where AODs are overestimated or underestimated. For example,
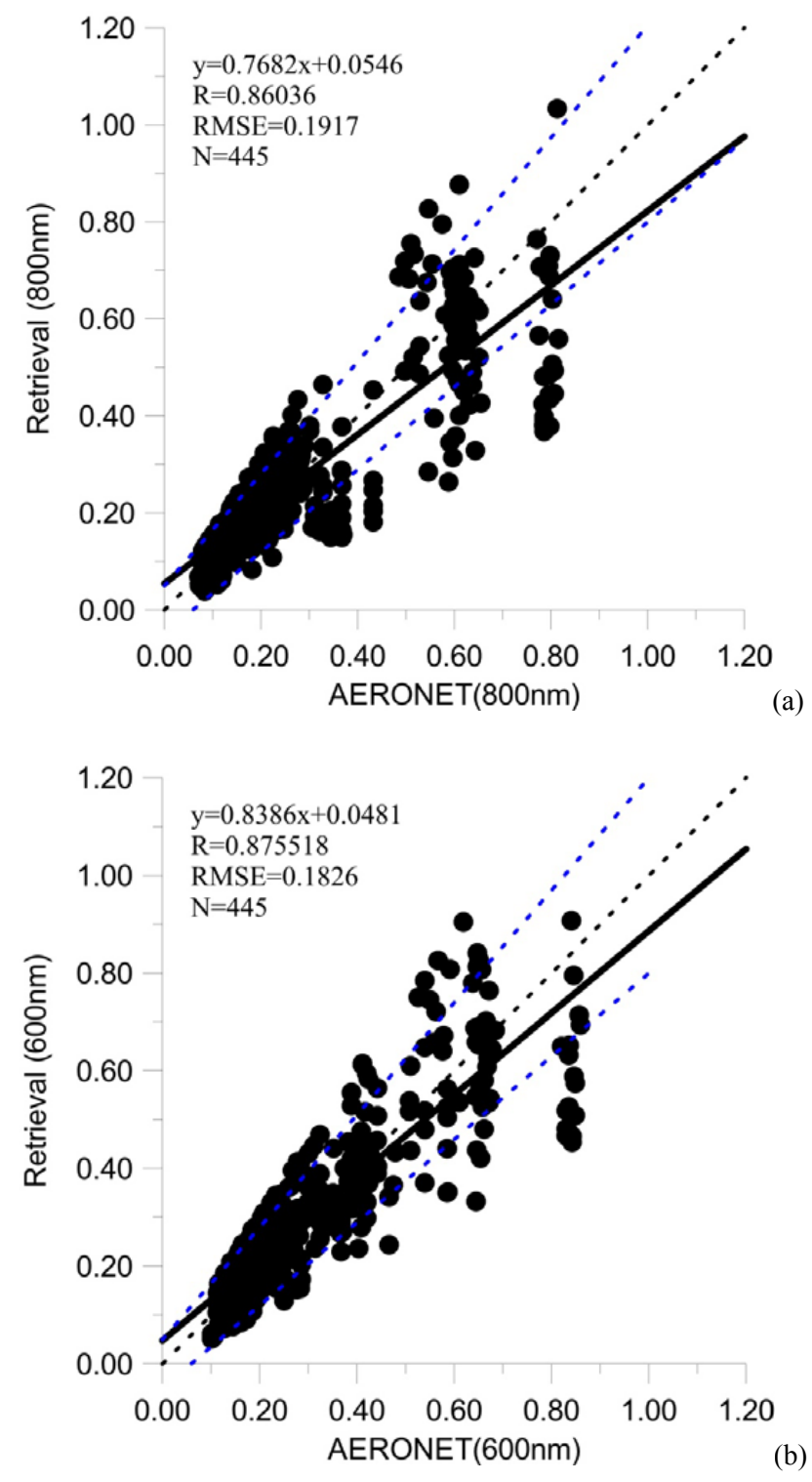

Fig. 7. Relationships between TS AOD and AERONET AOD at different wavelengths with a resolution of $10 \mathrm{~km}$ in the African area: (a) $0.8 \mu \mathrm{m}$, (b) $0.6 \mu \mathrm{m}$. The dashed (blue), dashed (black) and solid lines represent the error tolerance interval, the 1-1 line and the linear regression of the pre-sorted scatter plot, respectively. The text at the top describes the number of collocation (count), the regression curve, correlation $(R)$, and the RMS error of the fit.

at 08:45 UTC, the MSG/SEVIRI AOD is greatly overestimated at Tamanrasset_INM; the MSG/SEVIRI AOD value is about twice the AERONET AOD value. This overestimation is most likely due to residual cloud in a scene which results in high AOD. Additionally, the effect of residual gas absorption in the $0.8 \mu \mathrm{m}$ band may also contribute to the high value. Most retrieval values are similar to AERONET values in Saada with the exception of two times, 15:15 UTC and 17:00 UTC. The relative error at these two times is around 

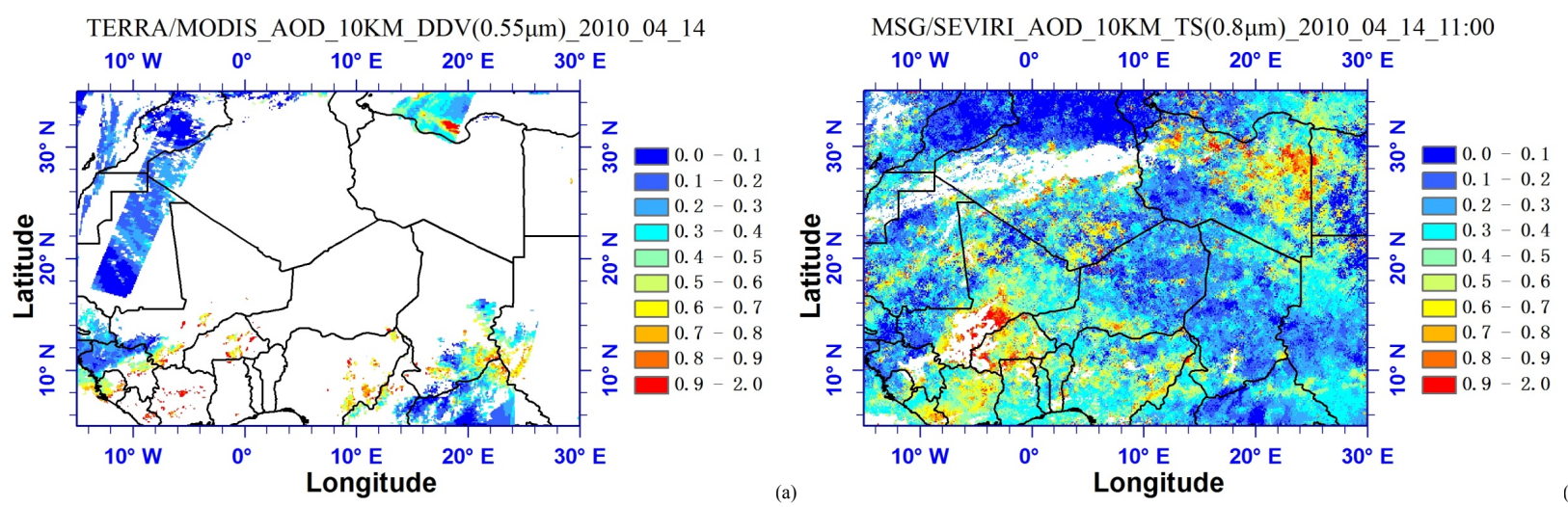

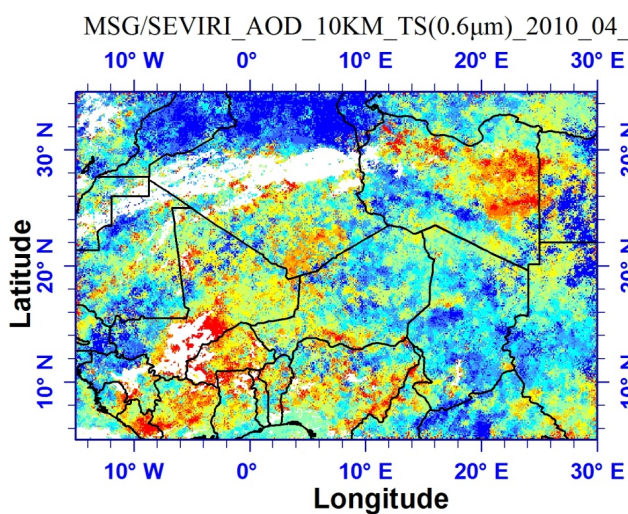

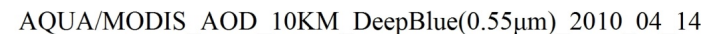

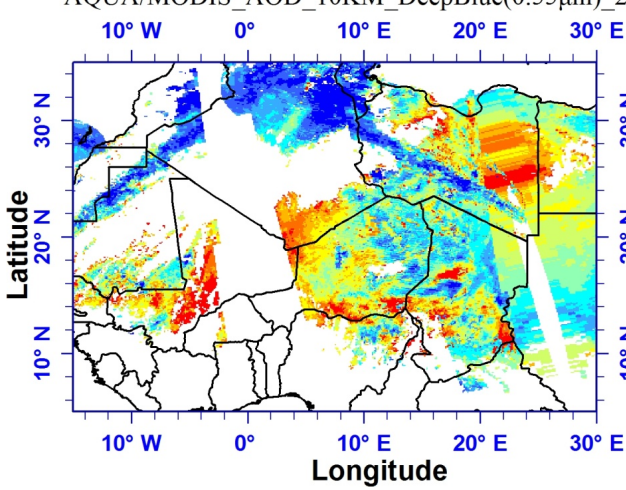

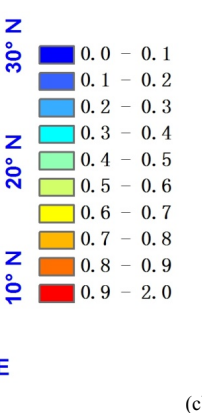

(c)

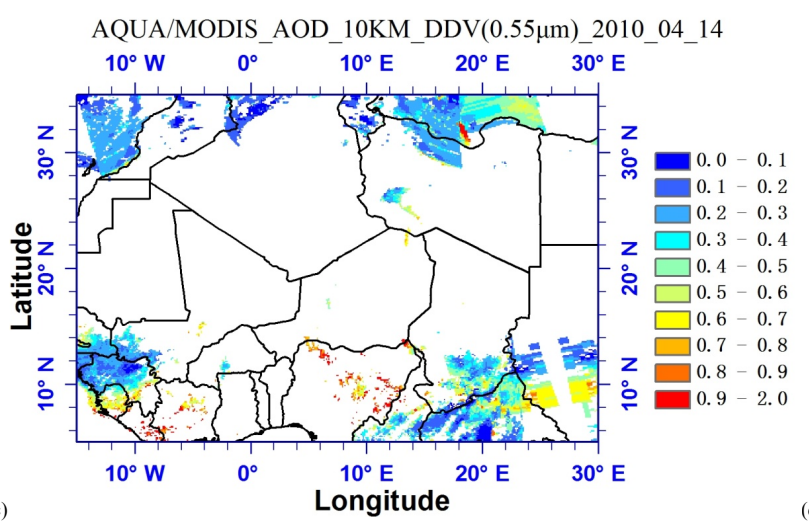

(d)

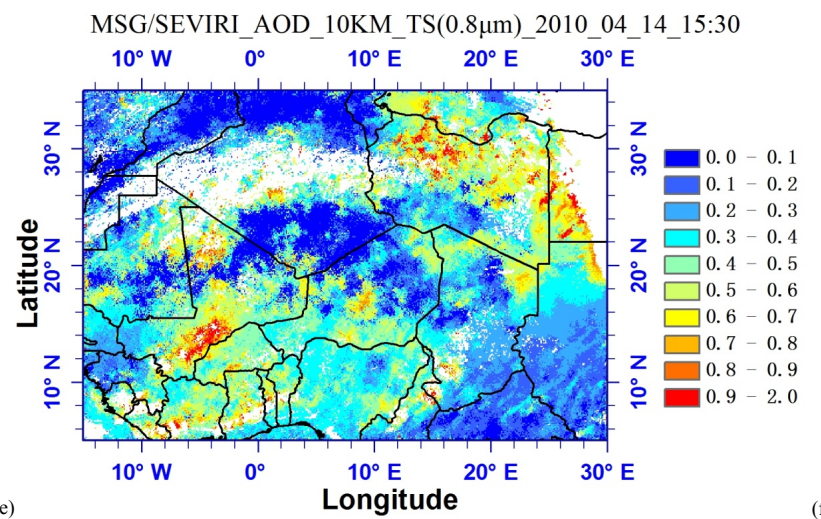

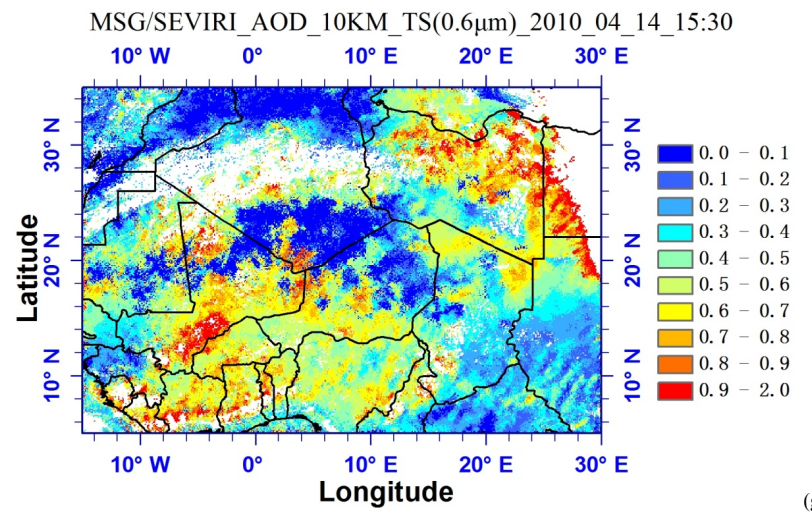

(g)

Fig. 8. (a) TERRA DDV products: (b) TS product at $0.8 \mu \mathrm{m}$ at 11:00 UTC, (c) TS product at $0.6 \mu \mathrm{m}$ at 11:00 UTC, (d) AQUA DDV product, (e) AQUA Deep Blue product, (f) TS product at $0.8 \mu \mathrm{m}$ at 15:30 UTC and (g) TS product at 0.6 $\mu \mathrm{m}$ at 15:30 UTC with a $10 \mathrm{~km}$ resolution in the Africa area on 14 April 2010. 


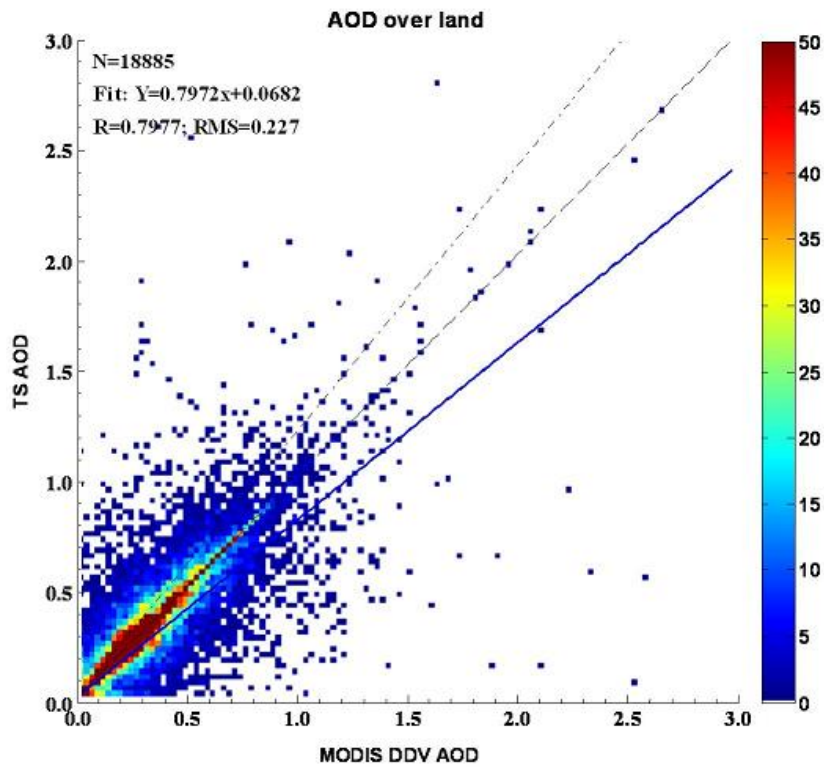

Fig. 9. Scatter plot of TS-derived data $(0.6 \mu \mathrm{m})$ versus NASA DDV aerosol products at $0.5 \mu \mathrm{m}$ at $10 \times 10 \mathrm{~km}$ over Africa on 14 April 2010. Data are sorted according to ordered pairs (MODIS DDV AOD, TS AOD) of AOD in 0.02 intervals, and colour represents the number of cases (colour bar) with those particular ordered pair values. The dashed, dotted and solid lines are the 1-1 line, error tolerance interval and the linear regression of the pre-sorted scatter plot, respectively. The text at the top describes the number of collocations $(N)$, the regression curve, correlation $(R)$ and the RMS error of the fit.

$25 \%$ compared with the AERONET results. The same situation is also observed in Carpentras with several high retrieval AOD values, which are most likely due to insufficient cloud screening.

A large error between MSG/SEVIRI and AERONET AODs is observed at the Hamburg site in the morning and at IER_Cinzana for the whole day. For Hamburg, a large error occurs at 09:00 UTC to 11:00 UTC (Fig. 5 - Hamburg). This large error may have been caused by a change in aerosol components, as described in Fig. 6. The Fine Mode Fraction (FMF) at $0.5 \mu \mathrm{m}$ fluctuates from 0.94 to 0.83 during the period from 09:00 UTC and 11:00 UTC, which implies that small particles are "inserted into" the atmosphere during this period. The change of aerosol components resulted in an incorrect choice of asymmetry factor and SSA (i.e., incorrect aerosol type). In addition, for IER_Cinzana, the MSG estimates of AOD are underestimated compared with the AERONET retrievals during the whole day. During this period, a large amount of vegetation burning was reported by MODIS Rapid Response System Global Fire Maps (http:// rapidfire.sci.gsfc.nasa.gov/firemaps/). Consequently, smoke aerosol concentrations are high (typically with AOD greater than 1 at $0.6 \mu \mathrm{m}$ ) during this period and are clearly identified in both the MSG and AERONET retrievals. However,

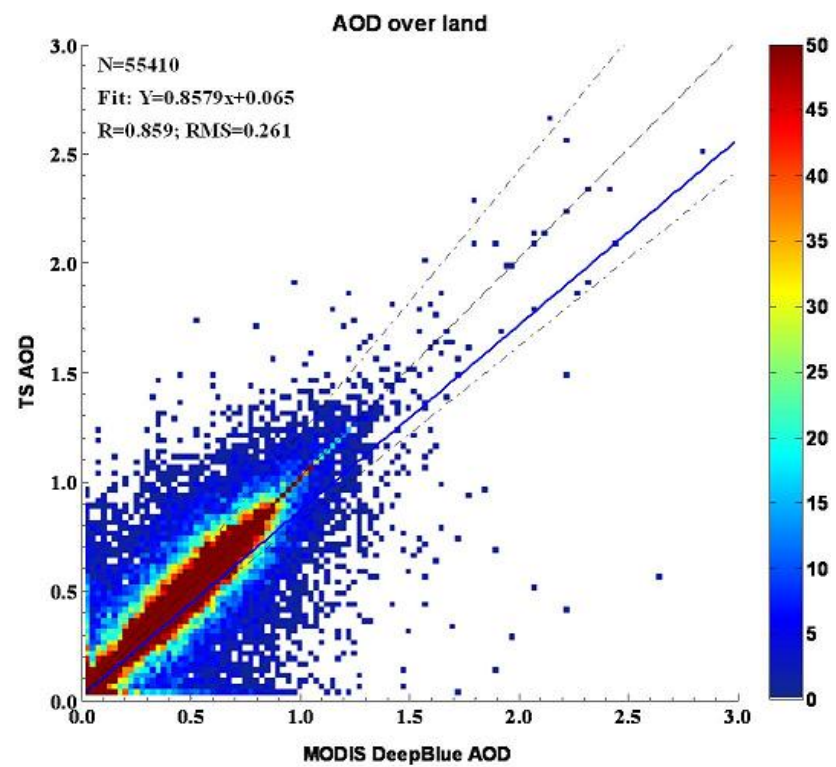

Fig. 10. Scatter plot of TS-derived data $(0.6 \mu \mathrm{m})$ versus NASA Deep Blue aerosol products for $0.5 \mu \mathrm{m}$ of $10 \times 10 \mathrm{~km}$ in the African area on 14 April 2010. Data are sorted according to ordered pairs (MODIS Deep Blue AOD, TS AOD) of AOD in 0.02 intervals, and colour represents the number of cases (colour bar) with those particular ordered pair values. The dashed, dotted and solid lines are the 1-1 line, error tolerance interval and the linear regression of the pre-sorted scatter plot, respectively. The text at the top describes the number of collocations $(N)$, the regression curve, correlation $(R)$ and the RMS error of the fit.

the MSG/SEVIRI AOD (around 0.8 at $0.6 \mu \mathrm{m}$ ) was lower than the AERONET AOD (around 1.2 at $0.6 \mu \mathrm{m}$ ); this result is primarily due to the incorrect aerosol type selection. Further investigation shows that the relative difference for different aerosol types was around or even larger than $100 \%$. Fig. 6 demonstrates that the FMF in IER_Cinzana was small throughout the whole day and varies greatly from morning to afternoon. Because there are only six predefined aerosol types with fixed single scattering albedo and asymmetry factors, which do not match well with the biomass burning aerosol type. In short, the new model works well with a stable and homogenous aerosol type during retrieval time and the accuracy is higher with large particles such as dust (e.g., at the Tamanrasset_INM site).

The AODs retrieved by the TS method at two wavelengths are compared with the AOD interpolated from AOD measurements at collocated AERONET sites in Fig. 7. The linear regression yielded a gradient of 0.77 , an offset of 0.05 with an $R$ of 0.86 , and RMSE of 0.19 at $0.8 \mu \mathrm{m}$ and a gradient of 0.84 , an offset of 0.05 with an $R$ of 0.88 , and RMSE of 0.18 at $0.6 \mu \mathrm{m}$. Most points are within the of $\pm 0.05 \pm 0.15 \tau$ error range (the blue dash line). For a higher AOD, approximately $60 \%$ of the points are within the $\pm 0.05 \pm 0.15 \tau$ error limit. Fig. 7 also shows that the TS algorithm works somewhat 

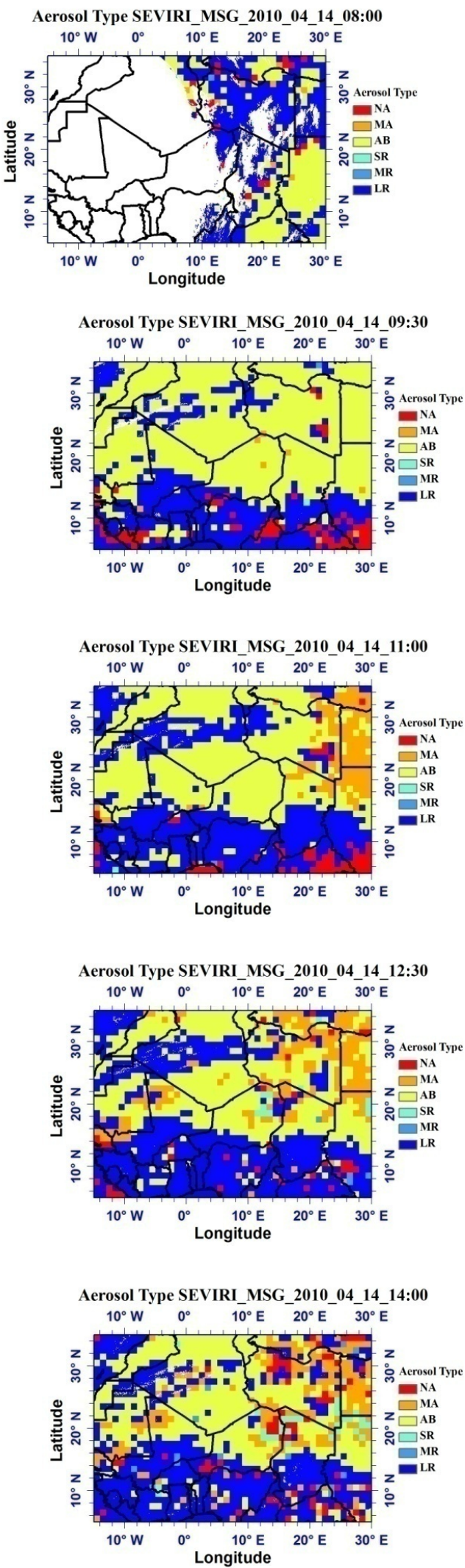
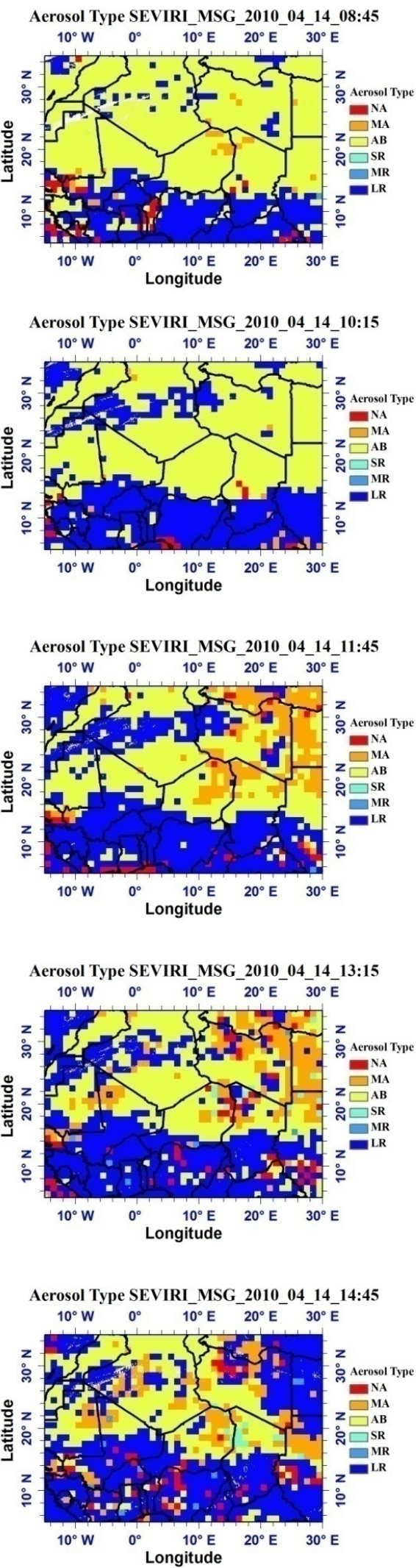

Fig. 11. Aerosol type in the African area on 14 April 2010 with time interval of 45 min. NA, MA, AB, SR, MR, LR stand for Spherical Non Absorbing, Spherical Moderately Absorbing, Spherical Absorbing, Non Spherical Small, Non Spherical Medium and Non Spherical Large respectively. 

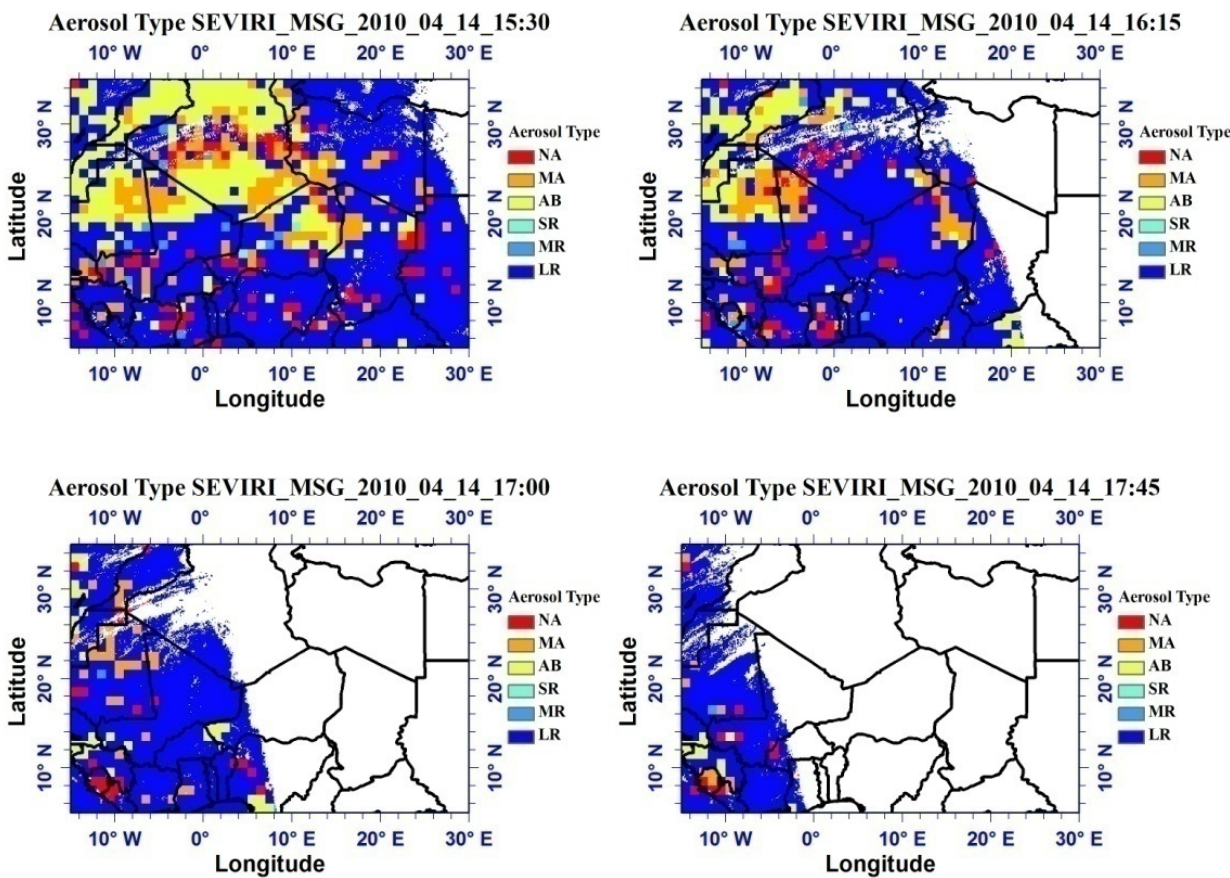

Fig. 11. Continued.
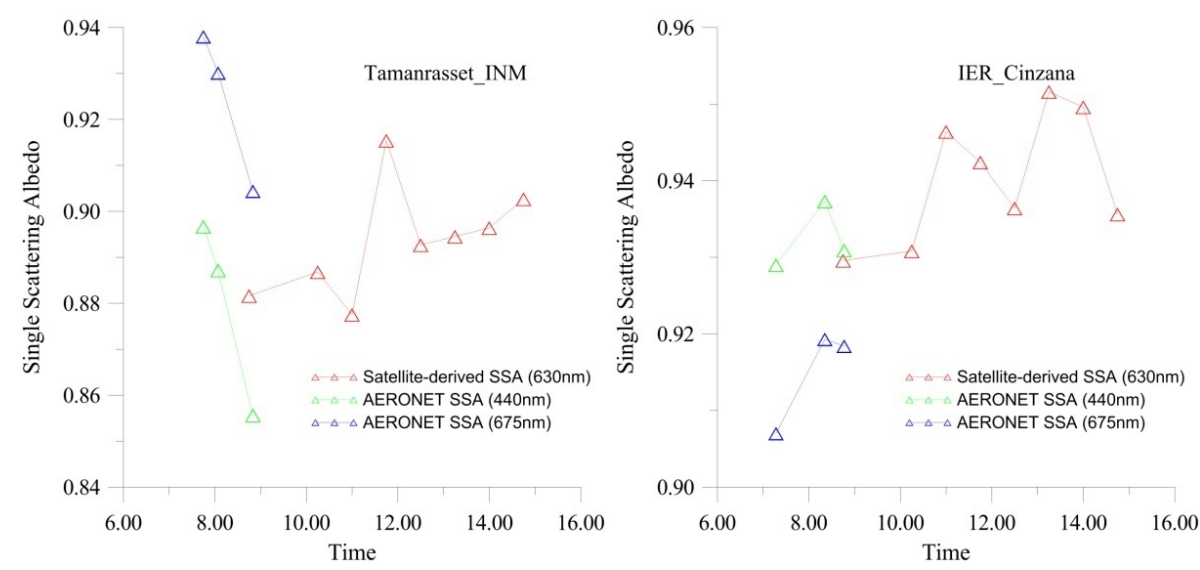

Fig. 12. The comparison of single scattering albedo derived from satellite data and measured at two AERONET sites, Tamanrasset_INM and IER_Cinzana. Here we show the derived SSA from 08:00 UTC till 15:00 UTC for the primary comparison.

better at $0.6 \mu \mathrm{m}$ than at $0.8 \mu \mathrm{m}$; this is especially true at higher AOD because of the possible contamination by trace gas absorption at $0.8 \mu \mathrm{m}$ and insufficient removal of this effect in Eq. (21).The non-zero intercepts in the regressions result from an improper representation of surface reflectance in the MSG/SEVIRI retrieval procedure while the deviation of the slopes from unity indicates a systematic bias resulting primarily from an inappropriate choice of the aerosol model in the MSG/SEVIRI retrieval algorithm (Ichoku et al., 2002; Remer et al., 2004).

\subsection{Satellite inter-comparisons}

The different aerosol products vary as much as they do because so many assumptions are required at different stages of the processing schemes (Grey and North, 2009). One criterion for assessing a new algorithm is to compare the validation statistics of the new algorithm-derived results with the validation results of the other products (Melin et al., 2007), in particular the generally used MODIS aerosol products. Melin et al. (2007) and Mei et al. (2012) gave several rules for satellite inter-comparisons. Before comparison using scattering plot between MSG and MODIS, we first resize the data onto the same resolution of $10 \mathrm{~km} \times 10 \mathrm{~km}$ 
and then the nearest overpass time of MSG compared with TERRA/MODIS and AQUA/MODIS is chosen. As an example, Fig. 8 shows the comparisons by considering the satellite overpass time of study area of Terra and Aqua satellites between TS retrieval AOD and NASA aerosol products, including DDV and Deep Blue AOD products. It is noted that the MODIS and MSG/SEVIRI spectral ranges are slightly different. The effective wavelengths for the mid-visible bands are 0.55 and $0.6 \mu \mathrm{m}$ for MODIS and SEVIRI, respectively. Because there are no Deep Blue products of TERRA, we compare the DDV product of TERRA with MSG/SEVIRI at 11:00 UTC in Fig. 9. We also compare DDV and Deep Blue products of AQUA and MSG/SEVIRI at 15:30 UTC in Fig. 10. The caption of each figure gives the wavelength, resolution, time and algorithm information. It can be observed that the DDV method may fail to retrieve AOD in the study area when the reflectance is high, and some retrieval values may not reliable; the Deep Blue algorithm works much better over bright surfaces. However, there are still many areas where both the Deep Blue and the DDV products do not provide an AOD value. The TS method seems to work well over the whole area except in the presence of clouds. The AOD distributions retrieved from MSG/SEVIRI and MODIS over the study area compare very well. However, in some areas, the TS method greatly underestimates the AOD; for example, in the southern part of Algeria, the AOD value retrieved by the TS method is low, which does not agree with the surrounding values. The primary reason for this underestimation may be an incorrect aerosol type selection because the aerosol here is a mixture of dust and biomass burning. In most areas, the trends of TS-derived AOD and the Deep Blue product compare well. The regression between AOD derived from the TS algorithm and the DDV product is shown in Fig. 9 while Fig. 10 displays the relationship between the TS method and the Deep Blue retrieved AODs. The correlation between AOD values derived by the TS algorithm and the Deep Blue method is 0.86 with a slope of 0.86 while the correlation between AODs from the TS algorithm and the DDV method is 0.80 with a slope of 0.80 . The two plots actually show rather similar agreement, given the completely different geographical areas and AOD ranges compared.

\subsection{Aerosol type analysis}

Without making a priori assumptions about the aerosol properties it is not possible to infer aerosol optical properties from current satellite retrievals (Bulgin et al., 2011). Six aerosol types were predefined by single scattering albedo and asymmetry factor; they are Spherical Non Absorbing, Spherical Moderately Absorbing, Spherical Absorbing, Non Spherical Small, Non Spherical Medium and Non Spherical Large. Then a retrieval cost function, Eq. (21), is used with prior assumptions on the aerosol spatial distribution and the temporal surface reflectance variation to accurately classify aerosol and get the best aerosol type during retrieval. Fig. 11 demon- strates the aerosol type distribution over Africa on 14 October, 2010. Two dominant aerosol types are found over this region, which are Spherical Absorbing and Non Spherical Large, different ratios of these two types corresponded to the dust aerosol type and the biomass burning aerosol type. The upper-left of the maps in Fig. 11 shows that these two aerosol types are consistently collocated along the African coast. More evidences are needed to suggest that dust and biomass burning aerosol are directly mixed (Bulgin et al., 2011). We can also find that the absorption character (Spherical Absorbing with $\omega=0.862$ ) is more obvious in the morning while the scattering character (Non Spherical Large with $\omega=0.965$ ) is dominant in the late afternoon. Meanwhile, the distinction between different aerosol types is much more obvious in the morning than in the afternoon. For instance, in the morning, the Spherical Absorbing aerosol type exclusively appeared in the north part while the Non Spherical Large aerosol type was only in the south part. However, in the middle of the day, more aerosol types such as Spherical Moderately Absorbing and Non Spherical Small were mixed, because the longer path through the atmosphere in the morning and afternoon enhance the contribution the signal reflected by aerosols (Wagner et al., 2010).

It is very difficult to validate the aerosol type. However, here we try to compare the aerosol type using single scattering albedo provided by AERONET. Due to the fixed value of the single scattering albedo and the asymmetry factor for each aerosol type, some differences are to be expected between satellite-derived aerosol types and AERONET measurements. Also, the wavelengths between satellite-derived data $(0.6 \mu \mathrm{m})$ and AERONET $(0.44,0.675$ and $0.87 \mu \mathrm{m})$ with different spectral resolution make it hard to compare. We use the $50 \mathrm{~km} \times 50 \mathrm{~km}$ averaged values to correspond with AERONET measurements. For this comparison we selected two AERONET sites which, according to the retrieved aerosol type distribution in North Africa, should be representative for the two main aerosol types in this area. One site is Tamanrasset INM $\left(5.53^{\circ} \mathrm{E}, 22.79^{\circ} \mathrm{N}\right)$, and the other one is IER_Cinzana $\left(-5.93^{\circ} \mathrm{E}, 13.28^{\circ} \mathrm{N}\right)$. The satellite data in Fig. 11 show that the aerosol at Tamanrasset_INM is much more absorbing as compared with IER_Cinzana, in good agreement with the AERONET observations shown in Fig. 12. The satellite-derived SSA at $0.6 \mu \mathrm{m}$ lies between the AERONET SSAs at 0.44 and $0.675 \mu \mathrm{m}$, which also agrees with the spectral characters of SSA.

\section{Conclusion}

A novel method has been proposed to simultaneously retrieve AOD and aerosol type. Six aerosol types were predefined, including both spherical and non-spherical particles, and the absorption was included in these aerosol types. We confined our consideration to one approximate method, which reduced the problem to solving a set of differential equations in the 
application to shortwave radiation transfer. After approximating the exact integrodifferential equation for radiative transfer by common differential equations for the upward and incident radiation fluxes, a relationship between the ground surface reflectance and apparent reflectance was proposed.

The algorithm has been proven to be capable of effectively separating the contributions from reflectance by the surface and by the atmosphere to the overall TOA observed reflected signal. The example results demonstrate that the TS algorithm shows good agreement with ground-based measurements of AOD as well as with current operational satellite aerosol products. The generic nature of the algorithm makes it suitable for a wide range of instruments. However, the plane parallel radiative transfer used in the model restricts the solar zenith angle range from $0^{\circ}$ to $80^{\circ}$. The predefined aerosol types in this paper should be improved in the future to cover a variety of atmospheric events such as biomass burning. Although this preliminary validation is encouraging, the difference in wavelengths and the time differences of various collection methods make comparisons difficult, and further validation is needed. This method is potentially useful for surface reflectance retrieval using SEVIRI observations which will be discussed in a following paper.

\section{Appendix A}

\section{List of symbols - standard alphabetical symbol}

\begin{tabular}{|c|c|}
\hline Symbol & Description \\
\hline$A$ & Earth's surface reflectance \\
\hline$A^{\prime}$ & $\begin{array}{l}\text { Earth's system reflectance (apparent re- } \\
\text { flectance observed from space) }\end{array}$ \\
\hline$A_{1, \lambda}$ & Surface reflectance at $\lambda$ at the first scan time \\
\hline$A_{2, \lambda}$ & $\begin{array}{l}\text { Surface reflectance at } \lambda \text { at the second scan } \\
\text { time }\end{array}$ \\
\hline$A^{\prime}(i)$ & $\begin{array}{l}\text { Apparent reflectance observed by satellite at } \\
\text { channel i }\end{array}$ \\
\hline$B\left(T_{e}(\tau)\right)$ & $\begin{array}{l}\text { Planck function at Absolute temperature } \\
\text { equal to } T_{\mathrm{e}}(\tau)\end{array}$ \\
\hline $\mathrm{C}_{\mathrm{vf}}$ & Fine-mode volume concentration $(\mu \mathrm{m})$ \\
\hline $\mathrm{C}_{\mathrm{vc}}$ & Coarse-mode volume concentration $(\mu \mathrm{m})$ \\
\hline$F_{\Theta}$ & $\begin{array}{l}\text { Solar flux density at the top of the atmo- } \\
\text { sphere when the instantaneous distance be- } \\
\text { tween the earth and sun is } r\end{array}$ \\
\hline$F^{\uparrow}(\tau)$ & $\begin{array}{l}\text { Total upward flux densities with atmosphere } \\
\text { optical depth equal to } \tau\end{array}$ \\
\hline$F^{\downarrow}(\tau)$ & $\begin{array}{l}\text { Total downward flux densities with atmo- } \\
\text { sphere optical depth equal to } \tau\end{array}$ \\
\hline$g$ & Asymmetry factor \\
\hline I & Intensity of the radiation \\
\hline$I(i)$ & $\begin{array}{l}\text { The measured radiance } \\
\mathrm{mWm}^{-2} \mathrm{sr}^{-1}\left(\mathrm{~cm}^{-1}\right)^{-1}\end{array}$ \\
\hline$i$ & Channel number \\
\hline
\end{tabular}

\begin{tabular}{ll}
\hline$k_{\lambda}$ & $\begin{array}{l}\text { Surface reflectance ratio at } \lambda \\
L\end{array}$ \\
$\begin{array}{l}\text { band solar irradiance at } 1 \mathrm{AU} \text { in } \\
\mathrm{m} \mathrm{Wm}^{-2} \mathrm{sr}^{-1}\left(\mathrm{~cm}^{-1}\right)^{-1}\end{array}$ \\
$P\left(\Omega,-\Omega_{0}\right)$ & $\begin{array}{l}\text { Number of predefined aerosol types } \\
\text { Phase function from direction }-\Omega_{0} \text { to di- } \\
\text { rection } \Omega\end{array}$ \\
$P\left(\Omega, \Omega^{\prime}\right)$ & $\begin{array}{l}\text { Phase function from direction } \Omega^{\prime} \text { to di- } \\
\text { rection } \Omega\end{array}$ \\
$r$ & Earth-sun distance \\
$r(t)$ & Sun-Earth distance in astronomical units \\
& (AU) at scan time $t$ \\
$r_{0}$ & Mean earth-sun distance \\
$r_{\mathrm{vf}}$ & Fine-mode volume median radius ( $\mu \mathrm{m})$ \\
$r_{\mathrm{vc}}$ & Coarse-mode volume median radius \\
& ( $\mu$ m) \\
$r_{\mathrm{ef}}$ & Fine-mode effective radius $(\mu \mathrm{m})$ \\
$r_{\mathrm{ec}}$ & Coarse-mode effective radius $(\mu \mathrm{m})$ \\
$\mathrm{S}$ & The solar constant $\left(1367 \mathrm{Wm}{ }^{-2}\right)$ \\
$\mathrm{S}_{0}$ & Percentage of spherical particles \\
$T_{e}$ & Absolute temperature \\
$T_{\lambda}$ & Transmissivity at $\lambda$ \\
$t$ & Satellite scan times \\
\hline
\end{tabular}

\section{Standard Greek symbols}

\begin{tabular}{|c|c|}
\hline Symbol & Description \\
\hline$\alpha$ & $\begin{array}{l}\text { Wavelength exponent in angstrom's turbid- } \\
\text { ity formula }\end{array}$ \\
\hline$\beta$ & Angstrom's turbidity coefficient \\
\hline$\varepsilon$ & $\begin{array}{l}\text { the minimal difference between surface re- } \\
\text { flectance of two orderly observations for } \\
\text { each predefined aerosol type }\end{array}$ \\
\hline$\theta$ & Solar zenith angle \\
\hline$\theta(t, x)$ & $\begin{array}{l}\text { Solar zenith angle in radians at scan time } \mathrm{t} \\
\text { and location } x\end{array}$ \\
\hline$\lambda$ & Wavelength \\
\hline$\mu$ & Cosine of satellite zenith angle \\
\hline$\mu_{0}$ & Cosine of solar zenith angle \\
\hline$\sigma_{\mathrm{f}}$ & Fine-mode radius standard deviation $(\mu \mathrm{m})$ \\
\hline$\sigma_{\mathrm{c}}$ & $\begin{array}{l}\text { Coarse-mode radius standard deviation } \\
(\mu \mathrm{m})\end{array}$ \\
\hline$\tau$ & Atmosphere optical depth \\
\hline$\tau_{0}$ & Total atmosphere aerosol optical depth \\
\hline$\tau_{\text {molecular }}$ & Rayleigh optical depth \\
\hline$\tau_{\text {aerosol }}$ & Aerosol optical depth \\
\hline$\tau(\lambda)$ & AOD at wavelength $\lambda$ \\
\hline$\Omega$ & Outgoing intensity direction \\
\hline$\Omega^{\prime}$ & Incoming intensity direction \\
\hline$-\Omega_{0}$ & Direct solar flux direction \\
\hline$\varpi$ & Single scattering albedo \\
\hline
\end{tabular}


Acknowledgements. This work was supported in part by the Ministry of Science and Technology (MOST) of China under Grant Nos. 2010CB950802 and 2010CB950803, and by the State Key Laboratory of Remote Sensing Science Innovation Program. L. L. Mei would like to thank the Director Prize under Grant No.Y1S02400CX from the Institute of Remote Sensing Applications of Chinese Academy of Sciences. The contribution of Gerrit de Leeuw was in part supported by the ESA-ESRIN project STSE-ALANIS Atmosphere Land Interaction Study, Theme 3 Aerosols. The authors would like to thank Yves M. Govaerts from EUMETSAT for his help with aerosol type selection. MSG data were available through EUMETSAT, and MODIS data were available through NASA MODIS LAADS. Many thanks are due to the principal investigators of the AERONET sites used in this paper for maintaining their sites and making their data publicly available, and to the AERONET coordination team for organizing and maintaining excellent and essential support for satellite retrieval development and validation.

Edited by: M. Van Roozendael

\section{References}

Bernard, E., Ramon, D., Jolivet, D., Moulin, C., Riedi, J., Deschamps, P.-Y., Nicolas, J.-M., and Hagolle, O.: Aerosol retrieval over land in the $635 \mathrm{~nm}$ channel of MSG/SEVIRI sensor: a hourly and daily AOT product above Europe, in Proceedings of the Eumetsat Meteorological Satellite Conference, Bath, Sept. 2009.

Bernard, E., Moulin, C., Ramon, D., Jolivet, D., Riedi, J., and Nicolas, J. M.: Description and validation of an AOT product over land at the $0.6 \mu \mathrm{m}$ channel of the SEVIRI sensor onboard MSG, Atmos. Meas. Tech., 4, 2543-2565, doi:10.5194/amt-42543-2011, 2011.

Bennouna, Y. S., de Leeuw, G., Piazzola, J., and KusmierczykMichulec, J.: Aerosol remote sensing over the ocean using MSG-SEVIRI visible images, J. Geophys. Res., 114, D23203, doi:10.1029/2008JD011615, 2009.

Breon, F. M., Tanré, D., Leconte, P., and Herman, M.: Polarized Reflectance of Bare Soils and Vegetation Measurements and Models, IEEE Trans. Geosci. Remote Sens., 33, 487-499, 1995.

Brindley, H. E. and Ignatov, A.: Retrieval of mineral aerosol optical depth and size information from Meteosat Second Generation SEVIRI solar reflectance bands, Remote Sens. Environ., 102, 344-363, 2006.

Bulgin, C. E., Palmer, P. I., Merchant, C. J., Siddans, R., Gonzi, S., Poulsen, C. A., Thomas, G. E., Sayer, A. M., Carboni, E., Grainger, R. G., Highwood, E. J., and Ryder, C. L.: Quantifying the response of the ORAC aerosol optical depth retrieval for MSG SEVIRI to aerosol model assumptions, J. Geophys. Res., 116, D05208, doi:10.1029/2010JD014483, 2011.

Carrer, D., Roujean, J. L., Hautecoeur, O., and Elias, T.: Daily estimates of aerosol optical thickness over land surface based on a directional and temporal analysis of SEVIRI MSG visible observations, J. Geophys. Res., 115, D10208, doi:10.1029/2009JD012272, 2010.

Chen, B. and Yang, Y.: MODIS aerosol optical thickness validation around Taiwan Strait and adjacent region, ACTA Oceanol. Sinica, 27, 170-176, 2005.
Curier, L., de Leeuw, G., Kolmonen, P., Sundstrom, Anu-Maija, Sogacheva, L., and Bennouna, Y.: Aerosol retrieval over land using the (A)ATSR dual-view algorithm, In Satellite Aerosol Remote Sensing over Land, edited by: Kokhanovsky, A. A. and de Leeuw, G., Chichester, UK, Praxis Publishing, 135-160, 2009.

de Leeuw, G., Schoemaker, R., Curier, L., Bennouna, Y., Timmermans, R., Schaap, M., Builtjes, P., and Koelemeijer, R.: AATSR derived aerosol properties over land. In Proceedings of ENVISAT Symposium 2007 held at Montreux, Switzerland, 23-27 April 2007 ESA SP-636, July 2007, 2007.

Deuze, J. L., Breon, F. M., Roujean, J. L., Deschamps, P. Y., Devaux, C., Herman, M., and Podaire, A.: Analysis of POLDER Airborne Instrument Observations over Land Surfaces, Remote Sens. Environ., 45,137-154, 1993.

Deuze, J. L., Breon, F. M., Devaux, C., Goloub, P., Herman, M., Lafrance, B., Maignan, F., Marchand, A., Nadal, F., Perry, G., and Tanré, D.: Remote sensing of aerosol over land surfaces from POLDER-ADEOS-1 polarized measurements, J. Geophys. Res., 106, 4913-4956, 2001.

Diner D. J., Martonchik J., Kahn R. A., Pinty, B. Gobron, N., Nelson, D. L., and Holben, B. N.: Using angular and spectral shape similarity constraints to improve MISR aerosol and surface retrievals over land. Remote Sens. Environ., 94, 155-171, 2005.

Eck, T. F., Holben, B. N., and Reid, J. S.: Wavelength dependence of the optical depth of biomass burning, urban, and desert dust aerosol. J. Geophys. Res., 104 31333, doi:10.1029/1999JD900923, 1999.

Flowerdew, R. J. and Haigh, J. D.: An approximation to improve accuracy in the derivation of surface reflectances from multi-look satellite radiometers, Geophys. Res. Lett., 22, 1693-169, 19956.

Gery, W. M. F. and North, P. R. J.: Aerosol optical depth from dualview (A)ATSR satellite observations, In Satellite Aerosol Remote Sensing over Land, edited by: Kokhanovsky, A. A. and de Leeuw, G., Chichester, UK, Praxis Publishing, 161-192, 2009.

Grey, W. M. F., North, P. R. J., Los, S. O., and Mitchell, R. M.: Aerosol optical depth and land surface reflectance multi-angle AATSR measurements: global validation and inter-sensor comparisons, IEEE Trans. Geosci. Remote Sens., 44, 2184-2197, 2006.

Govaerts, Y. M., Wagner, S., Lattanzio, A., and Watts, P.: Joint retrieval of surface reflectance and aerosol optical depth from MSG/SEVIRI observations with an optimal estimation approach: 1. Theory, J. Geophys. Res., 115, D02203, doi:10.1029/2009JD011779, 2010.

Herman, M., Deuze, J. L., Devaux, C., Goloub, P., Breon, F. M., and Tanré, D.: Remote Sensing of Aerosol over Land Surfaces Including Polarization Measurements and Application to POLDER Measurements, J. Geophys. Res., 102, 17039-17049, 1997.

Holben, B. N., Eck, T. F., Slutsker, I., Tanré, D., Buis, J. P., Setzer, A., Vermote, E., Reagan, J. A., Kaufman, Y. J., Nakajima, T., Lavenu, F., Jankowiak, I., and Smirnov, A.: AERONET - A federated instrument network and data archive for aerosol characterization, Remote Sens. Environ., 66, 1-16, 1998.

Hsu, N. C., Tsay, S. C., King, M. D., and Herman, J. R.: Aerosol Properties over Bright Reflecting Source Regions, IEEE Trans. Geosci. Remote Sens., 42, 557-569, 2004.

Ichoku, C., Chu, D. A., Mattoo, S., Kaufman, Y. J., Remer, L. A., Tanre, D., Slutsker, I., and Holben, B. N.: A spatio-temporal approach for global validation and analysis 
of MODIS aerosol products, Geophys. Res. Lett., 29, 8006, doi:10.1029/2001GL013206, 2002.

Kaufman, Y. J.: Measurements of the aerosol optical thickness and the path radiance - Implications on aerosol remote sensing and atmospheric corrections, J. Geophys. Res., 98, 2677-2692, 1993.

Kaufman, Y. J. and Sendra, C.: Algorithm for atmospheric corrections, Int. J. Remote Sens., 9, 1357-1381, 1988.

Kaufman, Y. J., Fraser, R. S., and Ferrare, R. A.: Satellite measurements of large-scale air pollution: Method, J. Geophys. Res., 95, 9895-9909, 1990.

Kaufman, Y. J., Tanré, D., Remer, L. A., Vermote, E. F., Chu, A., and Holben, B. N.: Operational remote sensing of tropospheric aerosol over land from EOS moderate resolution imaging spectroradiometer, J. Geophys. Res., 102, 17051-17067, doi:10.1029/96JD03988, 1997.

Kim, J., Yoon, J. M., Ahn, M. H., Sohn, B. J., and Lim, H. S.: Retrieving aerosol optical depth using visible and mid-IR channels from geostationary satellite MTSAT-1R, Int. J. Remote Sens., 29, 6181-6192, 2008.

Kim, J., Lee, J., Song, C. H., Kim, S., Chun, Y., Sohn, B., and Holben, B. N.: Characteristics of aerosol types from AERONET sunphotometer measurements, Atmos. Environ., 44, 3110-3117, 2010.

King, M. D., Kaufman, Y. J., Menzel, P., and Tanré, D.: Remote sensing of cloud, aerosol and water vapor properties from the Moderate Resolution Imaging Spectrometer (MODIS), IEEE Trans. Geosci. Remote Sens., 30, 1-27, 1992.

Knapp, K. R. and Vonder Haar, T. H.: Aerosol optical depth retrieval from GOES-8: Uncertainty study and retrieval validation over South America, J. Geophys. Res.-Atmos. 107, doi:10.1029/2001JD000505, 2002.

Knapp, K. P., Frouin, R., Kondragunta, S., and Prados, A.: Toward aerosol optical depth retrieval over land from GOES visible radiances: determining surface reflectance, Int. J. Remote Sens., 26 , 4097-4116, 2005.

Kokhanovsky, A. A., Deuzé, J. L., Diner, D. J., Dubovik, O., Ducos, F., Emde, C., Garay, M. J., Grainger, R. G., Heckel, A., Herman, M., Katsev, I. L., Keller, J., Levy, R., North, P. R. J., Prikhach, A. S., Rozanov, V. V., Sayer, A. M., Ota, Y., Tanré, D., Thomas, G. E., and Zege, E. P.: The inter-comparison of major satellite aerosol retrieval algorithms using simulated intensity and polarization characteristics of reflected light, Atmos. Meas. Tech., 3, 909-932, doi:10.5194/amt-3-909-2010, 2010.

Levy, R. C., Remer, L. A., and Dubovik, O.: Global aerosol optical properties and application to Moderate Resolution Imaging Spectroradiometer aerosol retrieval over land, J. Geophys. Res., 112, D13210, doi:10.1029/2006JD007815, 2007.

Levy, R. C., Remer, L. A., Kleidman, R. G., Mattoo, S., Ichoku, C., Kahn, R., and Eck, T. F.: Global evaluation of the Collection 5 MODIS dark-target aerosol products over land. Atmos. Chem. Phys., 10, 10399-10420, doi:10.5194/acp-10-10399-2010, 2010.

Liou, K. N.: An Introduction to Atmospheric Radiation, Second Edition, New York, USA, Academic Press, 2002.

Martonchik, J. V., Kahn, R. A., and Diner, D. J., Retrieval of aerosol properties over land using MISR observations, In Satellite Aerosol Remote Sensing over Land, edited by: Kokhanovsky, A. A. and de Leeuw, G., Chichester, UK, Praxis Publishing, 267268, 2009.
Mei, L. L., Xue, Y., Wang, Y., Hou, T. T., Guang, J., Li, Y. J., Xu, H., Wu, C. L., He, X. W., Dong, J., and Chen, Z. Q.: Prior information supported aerosol optical depth retrieval using FY2D data, in: Proceedings of the 2011 IEEE/IGARSS $t$ held at Vancouver, Canada, 24-29 July 2011, 2677-2680, 2011.

Mei, L. L., Xue, Y., Xu, H., Guang, J., Li, Y. J., Wang, Y., Ai, J. W., Qi, Y., and He, X. W.: Validation and analysis of optical thickness retrieval over land, Int. J. Remote Sens., 33, 781-803, 2012.

Melin, F., Zibordi, G., and Djavidnia, S.: Development and validation of a technique for merging satellite derived aerosol optical depth from SeaViFS and MODIS, Remote Sens. Environ., 108, 436-450, 2007.

Mishchenko, M. I., Geogdzhayev, I. V., Rossow, W. B., Cairns, B., Carlson, B. E., Lacis, A. A., Liu, L., and Travis, L. D.: Long term satellite record reveals likely recent aerosol trend, Science, 315, 1543, doi:10.1126/science.1136709, 2007.

North, P. R. J., Briggs, S. A., Plummer, S. E., and Settle, J. J.: Retrieval of land surface bi-directional reflectance and aerosol opacity from ATSR-2 multi-angle imagery, IEEE Trans. Geosci. Remote Sens., 37, 526-537, 1999.

Omar, A. H., Won, Jae-Gwang, Winker, D. M., Yoon, SoonChang, Dubovik, O., and McCormick, M. P.: Development of global aerosol models using cluster analysis of Aerosol Robotic Network (AERONET) measurements, J. Geophys. Res., 110, D10S14, doi:10.1029/2004JD004874, 2005.

Popp, C., Hauser, A., Foppa, N., and Wunderle, S.: Remote sensing of aerosol optical depth over central Europe from MSG-SEVIRI data and accuracy assessment with ground-based AERONET measurements, J. Geophys. Res., 112, D24S11, doi:10.1029/2007JD008423, 2007.

Remer, L. A., Tanre, D., Kaufman, Ichoku,Y. J., Mattoo, S., Levy, R., Chu, D. A., Holben, B., Dubovik, O., Smirnov, A., Martins, J. V., Li, R.-R., and Ahmad, Z.: Validation of MODIS aerosol retrieval over ocean, Geophys. Res. Lett., 29, 8008, doi:10.1029/2001GL013204, 2002.

Remer, L. A., Kaufman, Y. J., Tanré, D., Mattoo, S., Chu, D. A., Martins, J. V., Li, R. R., Ichoku, C., R. C., Kleidman, R. G., Eck, T. F., Vermote, E., and Holben, B. N.: The MODIS aerosol algorithm, products, and validation, J. Atmos. Sci., 62, 947-973, 2004.

Remer, L. A., Kaufman, Y. J., Tanre, D., Mattoo, S., Chu, D. A., Martins, J. V., Li, R. R., Ichoku, C., Levy, R. C., Kleidman, R. G., Eck, T. F., Vermote, E., and Holben, B. N.: The MODIS aerosol algorithm, products, and validation, J. Atmos. Sci., 62, 947-973, 2005.

Rondeaux, G. and Herman, M.: Polarization of Light Reflected by Crop Canopies, Remote Sens. Environ., 38, 63-75, 1991.

Spörl, U. and Deneke, H.: Toward a combined high-temporal resolution aerosol product from MODIS and METEOSAT SEVIRI, EGU General Assembly 2011 held in Vienna, Austria, 3-8 April 2011, 2011.

Tang, J., Xue, Y., Yu, T., and Guan, Y.: Aerosol optical thickness determination by exploiting the synergy of TERRA and AQUA MODIS, Remote Sens. Environ., 94, 327-334, 2005.

Thieuleux, F., Moulin, C., Bréon, F. M., Maignan, F., Poitou, J., and Tanré, D.: Remote sensing of aerosols over the oceans using MSG/SEVIRI imagery, Ann. Geophys., 23, 3561-3568, doi:10.5194/angeo-23-3561-2005, 2005. 
Thomas, G. E., Carboni, E., Sayer, A. M., Poulsen, C. A., Siddans, R., and Grainger R. G.: Oxford-RAL Aerosol and Cloud (ORAC): aerosol retrievals from satellite radiometers, In Satellite Aerosol Remote Sensing over Land, edited by: Kokhanovsky, A. A. and de Leeuw, G., Chichester, UK, Praxis Publishing, 193225, 2009.

Varotsos, C. A., Ondov, J. M., Cracknell, A. P., Efstathiou, M. N., and Assimakopoulos, M. N.: Long-range persistence in global Aerosol Index dynamics, Int. J. Remote Sens., 27, 3593-3603, 2006.

Veefkind, J. P., de Leeuw, G., Durkee, P. A., Russell, P. B., Hobbs, P. V., and Livingston, J. M.: Aerosol optical depth retrieval using ATSR-2 and AVHRR data during TARFOX, J. Geophys. Res.Atmos., 104, 2253-2260, 1999.
Wagner, S. C., Govaerts, Y. M., and Lattanzio, A.: Joint retrieval of surface reflectance and aerosol optical depth from MSG/SEVIRI observations with an optimal estimation approach: 2. Implementation and evaluation, J. Geophys. Res., 115, D02204, doi:10.1029/2009JD011780, 2010.

Wang, J., Christopher, S. A., Reid, J. S., Maring, H., Savoie, D., Holben, B. N., Livingston, J. M., Russell, P. B., and Yang, S.K.: GOES 8 retrieval of dust aerosol optical thickness over the Atlantic Ocean during PRIDE, J. Geophys. Res., 108, 8595, doi:10.1029/2002JD002494, 2003.

Xue, Y. and Cracknell, A. P.: Operational bi-angle approach to retrieve the Earth surface albedo from AVHRR data in the visible band, Int. J. Remote Sens., 16, 417-429, 1995. 